\title{
Response of the mesosphere to human-induced perturbations and solar variability calculated by a 2-D model
}

\author{
Rashid Khosravi, ${ }^{1}$ Guy Brasseur, ${ }^{2}$ Anne Smith, ${ }^{1}$ David Rusch, ${ }^{3}$ Stacy Walters, ${ }^{1}$ \\ Simon Chabrillat, ${ }^{4}$ and Gaston Kockarts ${ }^{4}$ \\ Received 21 August 2001; revised 21 February 2002; accepted 26 February 2002; published 27 September 2002.
}

[1] We have used the improved NCAR interactive 2-D model (SOCRATES) to investigate the chemical and thermal response of the mesosphere to composition changes from the preindustrial era $(\sim 1850)$ to the present, to doubling the $\mathrm{CO}_{2}$ concentration, and to the 11-year solar flux variability. The calculations show that all regions in the model mesosphere have cooled relative to the preindustrial times. The mesopause region has cooled by $\sim 5 \mathrm{~K}$ and the winter pole by up to $9 \mathrm{~K}$ near $60 \mathrm{~km}$. Ozone mixing ratio has decreased by about $5 \%$ in the lower mesosphere and by about $30 \%$ near the summer mesopause region (caused by a dramatic increase in $[\mathrm{OH}]$ ). Doubling the $\mathrm{CO}_{2}$ abundance cools the whole mesosphere by about $4-16 \mathrm{~K}$ and has a complicated effect on $\mathrm{O}_{3}$, which exhibits an alternating increase/decrease behavior from the lower mesosphere up to the mesopause region. Similar results are obtained, in both magnitude and structure, for the $\mathrm{O}_{3}$ response to a decrease in solar UV flux. Similarities are also found in the response of T, $\mathrm{OH}$, and $\mathrm{H}$ to these two perturbations. These results lead to the conclusion that the longterm increase in the well-mixed greenhouse gases, in particular $\mathrm{CO}_{2}$, alters the thermal structure and chemical composition of the mesosphere significantly and that these anthropogenic effects are of the same magnitude as the effects associated with the 11-year solar cycle. Thus, the difference in the timescales involved suggests that the anthropogenic signal over periods of typically 10 years is smaller than the signal generated by the 11 -year solar variability. Finally, analysis of the results from a simulation of the combined perturbations $\left(2 \times \mathrm{CO}_{2}+11\right.$-year solar variability $)$ shows that, for the most part, the solar variability does not interact with increasing $\mathrm{CO}_{2}$ and vice versa; that is, the two effects are additive. INDEX TERMS: 1610 Global Change: Atmosphere (0315, 0325); 1650 Global Change: Solar variability; 0315 Atmospheric Composition and Structure: Biosphere/atmosphere interactions; 0340

Atmospheric Composition and Structure: Middle atmosphere - composition and chemistry; 0325 Atmospheric Composition and Structure: Evolution of the atmosphere; KEYWORDS: climate change, mesosphere response, greenhouse gas, solar variability, doubling $\mathrm{CO}_{2}$, preindustrial

Citation: Khosravi, R., G. Brasseur, A. Smith, D. Rusch, S. Walters, S. Chabrillat, and G. Kockarts, Response of the mesosphere to human-induced perturbations and solar variability calculated by a 2-D model, J. Geophys. Res., 107(D18), 4358, doi:10.1029/ 2001JD001235, 2002.

\section{Introduction}

[2] The impact on the Earth's atmosphere of the increase in the concentrations of the well-mixed greenhouse gases $\left(\mathrm{CO}_{2}, \mathrm{CH}_{4}, \mathrm{~N}_{2} \mathrm{O}\right)$ has been an important topic of research in the atmospheric sciences over the past 2 decades. Although much of this research has focused on the response of the global climate system in the troposphere [e.g., Washington and Meehl, 1989; Rind et al., 1998; Soon et al., 1999; Meehl et al., 2000; Shindell et al., 2001], some recent studies have also investigated the impact of increase in $\mathrm{CO}_{2}$ on the

\footnotetext{
${ }^{1}$ National Center for Atmospheric Research, Boulder, Colorado, USA

${ }^{2}$ Max Planck Institute for Meteorology, Hamburg, Germany.

${ }^{3}$ Laboratory for Atmospheric and Space Physics, University of Colorado, Boulder, Colorado, USA.

${ }^{4}$ Belgian Institute for Space Aeronomy, Brussels, Belgium.

stratospheric polar ozone loss [Shindell et al., 1998a, 1998b].

[3] However, few investigations of climate change have been carried out for the middle atmosphere. Although life on Earth is more directly affected by climate change in the troposphere than in the middle and upper atmosphere, the radiative effects of an increase in the greenhouse gases, particularly $\mathrm{CO}_{2}$, become more pronounced at higher altitudes (decrease in optical depth). For example, the (diabatic) cooling of the mesosphere is directly determined by the abundance of $\mathrm{CO}_{2}$. As a result, the chemical composition and thermal (and hence dynamical) structure of the mesosphere may be altered substantially by human activities, which, through feedbacks, could affect the lower atmosphere.

[4] The mesosphere may thus be a region in which signature(s) of global change could be first detected [Thomas, 1996]. For example, the recently reported observed cooling over the last few decades in the mesosphere 
[Dunkerton et al., 1998; Keckhut and Kodera, 1999; Lysenko et al., 1999] and the increase in water vapor abundance in the middle atmosphere [Nedoluha et al., 1998] could be associated with human activities that lead to enhanced $\mathrm{CO}_{2}$ abundance. (Model results (Figures 2a, 5a, and 7) show that an increase in $\mathrm{CO}_{2}$ concentration warms up the tropical tropopause region, thereby allowing more water vapor to penetrate into the middle atmosphere.)

[5] However, enhanced $\mathrm{CO}_{2}$ concentration is not the only perturbation that can cause a cooling and an increase in water vapor abundance in the mesosphere. Since absorption of solar UV radiation by ozone and molecular oxygen is a significant source of heating in the lower and upper mesosphere, a decrease in solar flux also results in a cooling and an enhancement of the $\mathrm{H}_{2} \mathrm{O}$ abundance (slower photolysis). Thus, the net radiative effects of an increase in $\mathrm{CO}_{2}$ concentration and a decrease in solar UV flux are similar in the mesosphere. Furthermore, our model results (section 6) show that the net chemical effects of these two perturbations on ozone and odd hydrogen species are also similar. Although in the lower mesosphere a higher $\mathrm{CO}_{2}$ concentration increases the ozone abundance (cooler temperatures reduce ozone loss) whereas a lower solar flux decreases it, in the middle and upper mesosphere the perturbation in $\mathrm{CO}_{2}$ has effects on $\mathrm{O}_{3}, \mathrm{O}\left({ }^{3} \mathrm{P}\right), \mathrm{OH}$, and $\mathrm{H}$ that are similar in both magnitude and structure to the response induced by the declining phase of an 11-year solar cycle.

[6] This implies that it may not be easy to identify humaninduced perturbations, especially the increase in $\mathrm{CO}_{2}$ abundance, as the cause of climate change in the mesosphere. It is therefore important to analyze the effects of both anthropogenic and solar variability in detail, and to reveal any interactions that may exist between them. This is the objective of the research presented in this paper, which differs from the previous studies in the following respects: (1) in addition to investigating a $2 \times \mathrm{CO}_{2}$ scenario, an estimate of the change in the temperature and $\mathrm{O}_{3}$ distributions in the mesosphere since the pre-industrial era is obtained; (2) chemical effects of doubling the $\mathrm{CO}_{2}$ mixing ratio and 11-year solar variability in the mesosphere are presented and compared; and (3) interactions between solar variability and doubling the $\mathrm{CO}_{2}$ abundance are investigated.

[7] We note that variability in solar UV flux occurs not only over 27-day and 11-year periods, but may occur over centennial timescales as well [Lean and Rind, 1998]. The amplitude of the variability associated with the contemporary 11-year solar cycles has been measured over the last 2 decades and is well documented [Woods et al., 1996; Rottman, 1988]. However, multidecadal to centennial changes (over which the shorter-term cycles are superimposed) have not been measured, are uncertain, and their reconstruction remains very speculative [Lean, 2000]. Thus, we describe the change in solar input to our model atmosphere (section 4.3) by adopting for each wavelength the measured variation corresponding to the 11-year solar cycle. This approach leads us to compare the response of the mesosphere resulting from a long-term increase in $\mathrm{CO}_{2}$ concentration (the $2 \times$ $\mathrm{CO}_{2}$ scenario) with the response to the shorter-term 11-year variability in solar UV flux (section 6).

[8] The paper is organized as follows. A brief summary of the previous studies on the impacts of human-induced perturbations in the mesosphere is given in the next section.
Sections 3 and 4 contain descriptions of the model and scenarios, respectively. The results and discussion are given in sections 5-7, and the summary and conclusions in section 8 .

\section{Previous Studies}

[9] In comparing the response to various perturbations in the mesosphere from different models described below, it is important to note that large temperature changes modify the atmospheric scale height and hence change the altitude of a given pressure level. A predicted change in temperature on a constant altitude scale can thus be very different from that due to an identical perturbation that is calculated on a constant pressure scale. It should therefore be kept in mind that a direct comparison of the mesospheric response cannot be made between results from models that use altitude as the vertical dimension and those that use pressure or log pressure.

[10] One of the early studies of the effects in the mesosphere of doubling the $\mathrm{CO}_{2}$ concentration was that of Fels et al. [1980], in which they used the SKYHI general circulation model (GCM). Although the focus of their study was on the stratospheric impact of a $50 \%$ reduction in $\mathrm{O}_{3}$ and doubling the $\mathrm{CO}_{2}$ concentration (separately), their results also showed the thermal response of the mesosphere (the top boundary of their model was $\sim 80 \mathrm{~km}$ ). In their $2 \times \mathrm{CO}_{2}$ simulation the temperature in the mesosphere cooled by about $10 \mathrm{~K}$ just above the stratopause and by $\sim 8 \mathrm{~K}$ between 65 and $80 \mathrm{~km}$, with little latitudinal variation. However, their model did not include gravity waves, which have a strong influence on the thermodynamic structure of the mesosphere [Holton, 1982].

[11] Brasseur and Hitchman [1988] used an earlier version of the 2-D model of the present study (SOCRATES) to investigate the impact on ozone and temperature due to various scenarios of increasing the abundances of $\mathrm{CH}_{4}$, $\mathrm{N}_{2} \mathrm{O}$, chlorofluorocarbons (CFCs), and $\mathrm{CO}_{2}$, one of which was doubling the $\mathrm{CO}_{2}$ abundance. Although their focus was also in the stratosphere, their results extended to $\sim 70 \mathrm{~km}$ and showed a cooling of up to $16 \mathrm{~K}$ (due to $2 \times \mathrm{CO}_{2}$ ) in the lower mesosphere near the winter pole which decreased to $0 \mathrm{~K}$ at $\sim 68 \mathrm{~km}$ and turned into a warming of $\sim 2 \mathrm{~K}$ at $70 \mathrm{~km}$. This earlier version of SOCRATES did not include nonlocal thermodynamic equilibrium (non-LTE) treatment for cooling by $\mathrm{CO}_{2}$, and its top boundary was at $85 \mathrm{~km}$, which could affect the results at $70 \mathrm{~km}$.

[12] Roble and Dickinson [1989] ran a self-consistent 1-D global mean model of the mesosphere, thermosphere, and ionosphere to study the thermal and compositional changes in these regions due to doubling the $\mathrm{CO}_{2}$ and $\mathrm{CH}_{4}$ concentrations simultaneously. Their results showed that the mesosphere and thermosphere cooled by 10 and $50 \mathrm{~K}$, respectively, and that substantial changes in the chemical composition $\left(\mathrm{HO}_{\mathrm{x}}, \mathrm{O}_{\mathrm{x}}, \mathrm{NO}_{\mathrm{x}}, \mathrm{N}, \mathrm{N}_{2}\right)$ of these regions occurred as well. For example, atomic oxygen concentration increased by $\sim 26 \%$ in the mesosphere as a result of changes in both the chemistry and thermal structure of these regions. This was a pioneering study which showed that global change due to increase in greenhouse gases is not confined to the lower atmosphere.

[13] Rind et al. [1990] used the Goddard Institute for Space Studies (GISS) GCM model to investigate the effects 
of a $2 \times \mathrm{CO}_{2}$ perturbation on the temperature distribution and general circulation of the middle atmosphere, and in particular the stratosphere. Although their results for the change in temperature showed mostly a cooling, which agreed with those of other studies, they obtained a polar warming in both the winter stratopause and the summer mesopause regions, which contradicted previous results. As discussed in their paper, the mesopause discrepancy may be due to the proximity of the top boundary of their model ( 85 $\mathrm{km})$ and lack of non-LTE treatment of $\mathrm{CO}_{2}$ cooling above $75 \mathrm{~km}$. They attributed the polar warming in the winter stratopause to increased residual circulation, which resulted from the increased eddy energy in the middle atmosphere.

[14] Berger and Dameris [1993] implemented a detailed non-LTE algorithm for $\mathrm{CO}_{2}$ cooling in a global 3-D mechanistic model of the atmosphere $(0-150 \mathrm{~km})$ in order to study the impacts in the mesosphere and thermosphere of doubling $\mathrm{CO}_{2}$. They obtained a cooling throughout the mesosphere (and lower thermosphere), from $\sim 15 \mathrm{~K}$ near the summer pole in the lower mesosphere to $\sim 10 \mathrm{~K}$ near the mesopause region. They found a polar cooling near the stratopause in both winter and summer hemispheres. The cooling distribution they obtained in the thermosphere was opposite that of Roble and Dickinson [1989]: 40 K at $\sim 105 \mathrm{~km}$, decreasing to $\sim 2 \mathrm{~K}$ at $140 \mathrm{~km}$.

[15] Portmann et al. [1995] used an updated version of the Garcia-Solomon 2-D model [Garcia and Solomon, $1983,1985]$ to investigate the thermodynamic response of the mesosphere to doubling $\mathrm{CO}_{2}$. The most important update to their model consisted of replacing the Newtonian cooling in the mesosphere by an IR radiative model and implementing an accurate non-LTE code. They studied the role of dynamical feedbacks in the temperature response and found that without these feedbacks (i.e., with dynamical heating maintained at the same level as in the baseline case) the polar summer mesopause region warmed up. With dynamical feedbacks turned on, the warming disappeared and all of the mesosphere cooled in response to doubling the $\mathrm{CO}_{2}$ mixing ratio. They concluded that the increased $\mathrm{CO}_{2}$ abundance strengthens the pole-to-pole circulation in the mesosphere (upward in summer), which increases the cooling in the high latitude summer mesopause region.

[16] Thomas [1996], using the same updated 2-D model as that used by Portmann et al., studied the thermal response of the mesosphere due to doubling both $\mathrm{CO}_{2}$ and $\mathrm{CH}_{4}$ mixing ratios and showed that a global cooling of 5-10 K can occur in this region. He also argued that due to increased oxidation of $\mathrm{CH}_{4}$ and the warming of the tropical tropopause, the water vapor content of the mesosphere could increase by $50-100 \%$, which, combined with the large cooling, could result in an extension of the area coverage of the polar mesospheric clouds (PMCs) to midlatitudes. He concluded that such a scenario would make the PMCs visible from the Earth's surface at midlatitudes, and hence serve as the first signal of global change.

[17] Akmaev and Fomichev [1998] implemented a new parameterization of infrared radiative transfer in the15micron band of $\mathrm{CO}_{2}$ in a 3-D spectral model of the mesosphere and lower thermosphere (MLT) to study the effects of $\mathrm{CO}_{2}$ doubling. Their model included many of the important processes in the MLT region such as molecular viscosity, thermal conductivity, gravity wave breaking and momentum deposition, chemical heating, tidal forcing, and absorption of extreme $\mathrm{UV}$ by $\mathrm{O}, \mathrm{O}_{2}$, and $\mathrm{N}_{2}$. However, it did not include interactive chemical feedbacks that are particularly important in the stratosphere and which could be important in the upper mesosphere for chemical heating. They found an average cooling at the stratopause of $\sim 14 \mathrm{~K}$, decreasing to $\sim 8 \mathrm{~K}$ near the mesopause region and increasing again to $40-50 \mathrm{~K}$ at about $150 \mathrm{~km}$. They also found that tides in the MLT region could have as much as $\pm 5 \mathrm{~K}$ effect on the thermal response of this region, and that the thermal shrinking (density decrease) of $40-45 \%$ due to the cooling could lead to an apparent warming, particularly in the lower thermosphere.

[18] Akmaev and Fomichev [2000] estimated the thermal response of the MLT region to the $\mathrm{CO}_{2}$ increase over the last $3-4$ decades by using the same 3-D model as that in their 1998 study and updating the $\mathrm{CO}_{2}$-cooling parameterization. They found that the response was mostly negative, with a globally averaged cooling of $3 \mathrm{~K}$ at about $60 \mathrm{~km}$ which decreases to $\sim 1 \mathrm{~K}$ near $100 \mathrm{~km}$ and grows to $10-15 \mathrm{~K}$ at higher altitudes in the thermosphere. The vertical profile of their cooling calculation agreed well with observations, but the magnitude was smaller by $2-10$ times. They concluded that other mechanisms such as ozone depletion during the last 3-4 decades might have contributed substantially to the cooling of the MLT region (their model did not include chemical feedbacks).

[19] It is clear from the above review that these previous investigations have focused primarily on the thermal response of the mesosphere to a $2 \times \mathrm{CO}_{2}$ perturbation. Only the studies by Brasseur et al. [1988] and Roble and Dickinson [1989] addressed the response of $\mathrm{O}_{3}$ and other constituents (latter study). However, the analysis in the former study did not extend to the mesopause (and did not include non-LTE effects for $\mathrm{CO}_{2}$ cooling), and the latter study used a 1-D global average model, which cannot treat dynamical feedbacks or latitudinal variations.

[20] In contrast, we present a global picture of the chemical (and thermal) response of the mesosphere to doubling the $\mathrm{CO}_{2}$ concentration and to solar flux variations. We use a 2-D model that treats most of the mesospheric physical processes that are important in quantifying the effects of the two perturbations (section 3). These processes include gravity wave breaking and momentum deposition, non-LTE cooling in the 15-micron band of $\mathrm{CO}_{2}$, solar and chemical heating, molecular diffusion, and detailed treatment of dynamics (transformed Eulerian mean). In addition, the model treats these radiative, dynamical, and chemical processes interactively. One shortcoming of our analysis, which is an inherent limitation of all 2-D models, is the lack of treatment of diurnal tides in the mesosphere. This may have a significant impact on the thermal response of the MLT region [Akmaev and Fomichev, 1998], but it can be properly treated only in a 3-D model. However, interactive 3-D models of the middle atmosphere are currently in the development stage.

\section{Model Description}

[21] The simulations were performed with the improved version of the NCAR 2-D model described by Brasseur et al. [1990]. The new version of the model, called SOCRATES (Simulation Of Chemistry, RAdiation, and Transport of 
Environmentally Important Species), extends from pole to pole and from the Earth's surface to the lower thermosphere (120 km in log-pressure altitude). The horizontal and vertical resolutions are $5^{\circ}$ and $1 \mathrm{~km}$, respectively, and the most important improvements since the 1990 version include (1) extension of model vertical domain to $120 \mathrm{~km}$ to include mesospheric and thermospheric processes (e.g., molecular diffusion); (2) implementation of a UV radiative transfer model that accounts for multiple scattering by air molecules and aerosols [Shettle and Weinman, 1970]; (3) adoption of the updated IR radiation code from NCAR's Community Climate Model (CCM) [Briegleb, 1992]; (4) implementation of a non-LTE algorithm [Fomichev et al., 1998] for calculation of IR cooling by $\mathrm{CO}_{2}$ in the upper mesosphere and lower thermosphere; (5) implementation of a gravity wave model [Lindzen, 1981]; (6) lowering of the circulation boundary condition to $2 \mathrm{~km}$ (from $15 \mathrm{~km}$ ), which is now determined from physical principles; (7) implementation of a semi-Lagrangian transport scheme [Robert, 1981] for chemical species; (8) parameterization of convective- and frontalinduced vertical transport in the troposphere [Langner et al., 1990]; (9) improvement of the chemical solver; (10) updated chemistry (JPL 2000, available at http://jpldataeval.jpl.nasa. gov); and (11) implementation of a diurnal variation scheme in the chemistry module.

[22] Full details of the model physics and chemistry, including mathematical formulations, tables of solar flux and chemical reactions and rate constants, lower and upper boundary conditions for transported species, initial values, numerical methods, and model results are given by Huang et al. [1998], and are available on the web at http://acd.ucar. edu/models/socrates/socrates.html. In the following, we give a brief description of the most important features of the radiation, dynamics, and chemistry sections in the model.

\subsection{Radiation}

[23] The net diabatic heating rate is calculated as a balance between solar heating by ozone (UV, visible) and molecular oxygen (UV), chemical heating in the mesosphere and lower thermosphere by exothermic reactions involving odd hydrogen and odd oxygen species [Brasseur and Offermann, 1986], and IR cooling by radiatively active gases. These calculations are described below.

\subsubsection{Solar and Chemical Heating}

[24] The solar heating associated with absorption of UV radiation by ozone and molecular oxygen is calculated by integration of the radiative transfer equation using the deltaEddington method [Shettle and Weinman, 1970; Joseph et al., 1976] to obtain the radiation field as a function of wavelength and optical depth. The input solar flux (photons/ $\mathrm{cm}^{2} / \mathrm{s}$ ) and absorption cross sections are specified over the wavelength region $117-730 \mathrm{~nm}$. The solar spectrum used at the top of the model atmosphere is taken from two sources. In the wavelength range of $120-417 \mathrm{~nm}$, the measurements by the Solar Stellar Intercomparison Experiment (SOLSTICE) [Woods et al., 1996] onboard the Upper Atmospheric Research Satellite (UARS) [Reber, 1993] are used. For wavelengths larger than $417 \mathrm{~nm}$, the data from World Meteorological Organization [1986] (WMO) are adopted. For the baseline model atmosphere and simulations that do not involve solar flux variability, the solar fluxes (from SOLSTICE) are taken from the average of values from 1
January through 31 March 1992 (representing solar maximum conditions), and from 1 January through 29 March 1995 (representing solar minimum conditions). The solar flux in the model is adjusted to account for the ellipticity of the Earth's orbit, and the model uses the 24-hour average of the solar heating rate.

[25] The absorption cross sections and quantum yields are taken mostly from DeMore et al. [1997]. An important exception is for absorption of UV radiation by $\mathrm{O}_{2}$ in the Schumann-Runge bands, which is treated by using the parameterization of Kockarts [1994]. This method uses recent spectroscopic data for $\mathrm{O}_{2}$, accounts for temperature dependence of its cross section, and remains valid when the slant optical depth of $\mathrm{O}_{2}$ becomes very large. Temperature dependence of absorption cross sections of other species such as $\mathrm{O}_{3}, \mathrm{~N}_{2} \mathrm{O}, \mathrm{NO}_{2}$, and $\mathrm{HNO}_{3}$ are also included in the radiation model.

[26] The calculation of heating rate due to absorption of UV radiation includes chemical heating [Brasseur and Offermann, 1986], which is the heat released by the recombination of the photolysis products of $\mathrm{O}_{2}$ and $\mathrm{O}_{3}$ $\left(\mathrm{O}\left({ }^{1} \mathrm{D}\right)\right.$ and $\left.\mathrm{O}\left({ }^{3} \mathrm{P}\right)\right)$, away from the region of $\mathrm{UV}$ absorption [Brasseur and Solomon, 1986]. Furthermore, reduction of UV heating rates due to airglow processes and of chemical heating rates due to chemiluminescence is accounted for by adopting the heating efficiencies of Mlynczak and Solomon [1993].

\subsubsection{Infrared Cooling}

[27] The IR radiative calculations for altitudes between 0 and $50 \mathrm{~km}$ are based on the long wave band model described by Briegleb [1992]. The algorithm, which is adopted from the NCAR CCM, uses a modified Malkmus random band model [Goody and Yung, 1989] to compute broadband absorption and emission by $\mathrm{CO}_{2}, \mathrm{H}_{2} \mathrm{O}, \mathrm{O}_{3}, \mathrm{CH}_{4}$, $\mathrm{N}_{2} \mathrm{O}, \mathrm{CFC} 11, \mathrm{CFC} 12$, and aerosols. The spectral range of this model is from 0 to $3000 \mathrm{~cm}^{-1}$ with a resolution of 100 $\mathrm{cm}^{-1}$, and a correction is applied for the overabsorption that is present in traditional Malkmus band models.

[28] Above $60 \mathrm{~km}$ altitude, where local thermodynamic equilibrium (LTE) does not hold for radiative emissions by $\mathrm{CO}_{2}$, and where the contributions to the IR cooling by radiatively active gases other than $\mathrm{CO}_{2}, \mathrm{H}_{2} \mathrm{O}$, and $\mathrm{O}_{3}$ are negligible, the cooling is calculated by the parameterization of Fomichev et al. [1998] for $\mathrm{CO}_{2}$ and $\mathrm{O}_{3}$ (LTE). This algorithm calculates the non-LTE cooling in the $15-\mu \mathrm{m}$ band of $\mathrm{CO}_{2}$ as a function of $\mathrm{CO}_{2}$ mixing ratio and provides explicit dependence of the cooling rate on atmospheric temperature, composition, and the quenching rate constants. It is also computationally efficient and accurate. For the (LTE) cooling due to the rotational band of $\mathrm{H}_{2} \mathrm{O}$ we have adopted the parameterization given by Fomichev et al. [1986].

[29] In the 50-60 km altitude range, a linear interpolation is applied to the IR cooling rates in order to insure a smooth transition between the two methods of cooling rate calculations.

\subsection{Dynamics}

[30] The dynamical fields of wind velocity and potential temperature are obtained by solving the equations of thermodynamics, zonal momentum, mass continuity, and thermal winds in the transformed Eulerian mean (TEM) 
framework using log-pressure altitude as the vertical coordinate [see Brasseur et al., 1990; Garcia and Solomon, 1983]. The dynamical forcing is provided by the dissipation of planetary waves of wave numbers 1 and 2 from a simplified wave model [Garcia, 1991] and by parameterized gravity wave breaking [Lindzen, 1981]. The wind acceleration (proportional to Eliason-Palm (EP) flux divergence) is a function of the mean zonal wind, so that the wave components respond to, and interact with, the mean zonal flow. Diffusive mixing coefficients in the meridional and vertical dimensions are generated by dissipation of planetary and gravity waves, respectively, and affect the transport of heat and chemical species.

[31] The EP flux divergence for planetary waves is calculated by using the linear-wave form of the vorticity and thermodynamic equations, following Smith and Avery [1987]. These equations are combined into a single equation of the planetary wave geopotential, $\Phi^{\prime}$, which is solved (using the algorithm of Lindzen and Kuo [1969]) for prescribed values of the geopotential waves (amplitude and phase) at 100 mbar. This lower boundary forcing is specified according to climatological values [Randel, 1987]. From the wave stream function, the zonal and meridional wind velocities as well as the momentum flux divergence are calculated. The meridional planetary wave diffusion coefficient $\left(\mathrm{K}_{\mathrm{yy}}\right)$ is obtained according to the model of Garcia [1991]. In the troposphere, the EP flux divergence is specified (with seasonal variation) according to the climatology established by Randel [1992]. For gravity waves, the Lindzen-Holton breaking scheme [Lindzen, 1981; Holton, 1982] is adopted for estimating the corresponding momentum flux divergence and vertical eddy diffusion coefficient $\left(\mathrm{K}_{\mathrm{zz}}\right)$.

\subsection{Chemistry}

[32] The model chemistry includes 52 species and 137 gas-phase, 5 heterogeneous (PSC and aerosols), and 46 photodissociation reactions. The reaction rate coefficients are taken from the JPL 2000 compilation. The chemistry solver is based on a backward Euler scheme in which the full set of nonlinear partial differential equations for the concentrations of the species is solved simultaneously. The time step is one quarter of the length of day during daytime and one quarter of the length of night during nighttime ( 3 hours at equinox). To resolve the transition from day to night and vice versa, the time step at sunrise and sunset is subdivided into four shorter intervals, so that a total of 14 time steps are used. The diurnal variation in solar flux and hence in the concentration of species is accounted for.

\subsection{Model Evaluation}

[33] To obtain accurate results when investigating climate change using chemical transport models, it is important that the unperturbed (baseline) state of the atmosphere calculated by the model corresponds closely to the observed state. The baseline state of the present day atmosphere in January as predicted by the SOCRATES model is compared in Figure 1 with measured data for the zonally averaged distributions of temperature $(T)$ and zonal wind $(\bar{u})$, and the mixing ratios of water vapor, methane, and ozone. The observed $T$ and $\bar{u}$ fields are obtained from the COSPAR
International Reference Atmosphere (CIRA), and the $\mathrm{H}_{2} \mathrm{O}$, $\mathrm{CH}_{4}$, and $\mathrm{O}_{3}$ fields are those of the UARS Reference Atmosphere Project (available at http://code916.gsfc.nasa. gov/Public/Analysis/UARS/urap/home.html).

[34] The model captures many important features apparent in the measured data. For example, it reproduces the temperature minimum of less than $200 \mathrm{~K}$ at the tropical tropopause and simulates the "separated stratopause" discussed by Hitchman et al. [1989]. However, the altitude of the winter "stratopause" in the model $(\sim 70 \mathrm{~km})$ is significantly higher than the observed altitude $(\sim 55 \mathrm{~km})$, indicating that the gravity waves break too high in the model atmosphere. The mesopause height calculated by the model is at about $85 \mathrm{~km}$ in summer and near $100 \mathrm{~km}$ in winter, in good agreement with observations. The calculated temperature minimum, however, is $10-20 \mathrm{~K}$ higher than observed, suggesting that the upward air motion generated by momentum deposition that is associated with gravity wave breaking is too weak.

[35] The zonally averaged zonal wind is derived in the model by assuming geostrophic balance with the zonal mean temperature. As expected, the wind is directed eastward in the winter stratosphere and mesosphere up to $80-90 \mathrm{~km}$, where it reverses in response to the gravitywave-generated zonal torque. The maximum zonal wind near $60 \mathrm{~km}$ altitude is of the order of $80 \mathrm{~m} / \mathrm{s}$, i.e., larger than the climatological values of $60-70 \mathrm{~m} / \mathrm{s}$. In the summer stratosphere, the winds are directed westward with maximum speed of $50-60 \mathrm{~m} / \mathrm{s}$, in good agreement with observations. Wind reversal is predicted above 90 $\mathrm{km}$, consistent with observations. However, the measured data show a stronger wind reversal in the summer hemisphere than in the winter hemisphere that is not predicted by the model. In the tropics, where geostrophic conditions do not hold and the zonal wind speeds are extrapolated from their extratropical values, the agreement between model and observed data is not good.

[36] Water vapor calculated in the model is characterized by increasing mixing ratios from the tropopause (about 3 ppmv) to the stratopause $(5.2-5.5 \mathrm{ppmv})$. Similar vertical gradients are seen in the measured data, but with somewhat higher values (about 3.6-4.0 ppmv near the tropopause and 6.0-6.4 ppmv near the stratopause). In the case of methane, the calculated and observed distributions are also in reasonably good agreement. However, the meridional mixing of long-lived tracers in the model seems to be too strong, and the model underestimates the strength of the subtropical and polar dynamical barriers. Finally, the global distribution of ozone derived by the model is in good agreement with the observed values. The calculated mixing ratios reach a maximum of $10 \mathrm{ppmv}$ at about $32 \mathrm{~km}$ in the tropics and are very close to the observed values near the stratopause.

[37] An important aspect of the distribution of water vapor in the atmosphere, which is relevant to the results obtained in this study, is its transport across the tropical tropopause into the stratosphere. Air parcels become dryer as they penetrate into the lower stratosphere because the cold temperatures in the tropical tropopause freeze the amount of the parcels' water vapor that is in excess of the saturation vapor pressure of water over ice [Brewer, 1949]. Since this process is strongly temperature dependent, the seasonal variation of the tropical tropopause temper- 

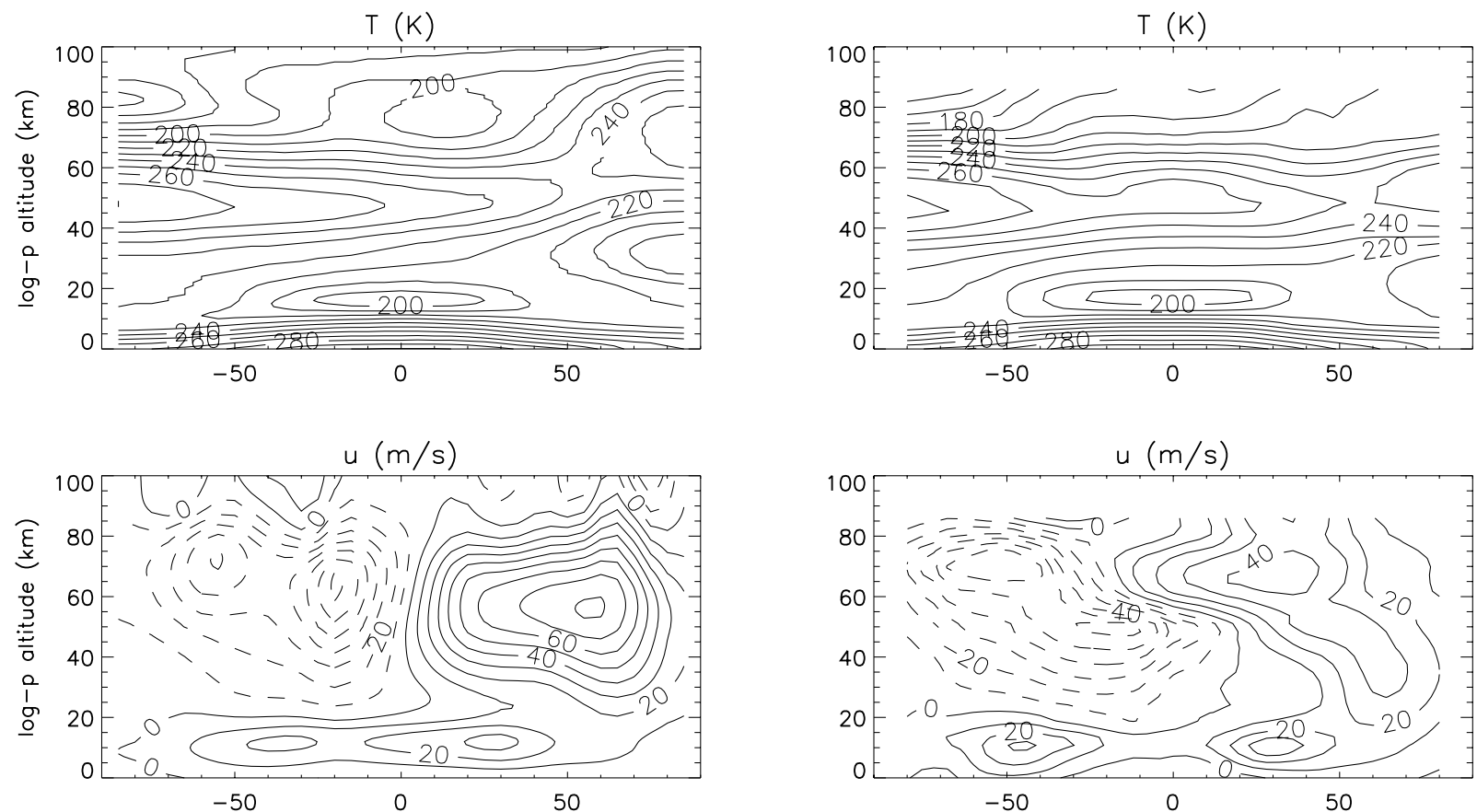

$u(m / s)$
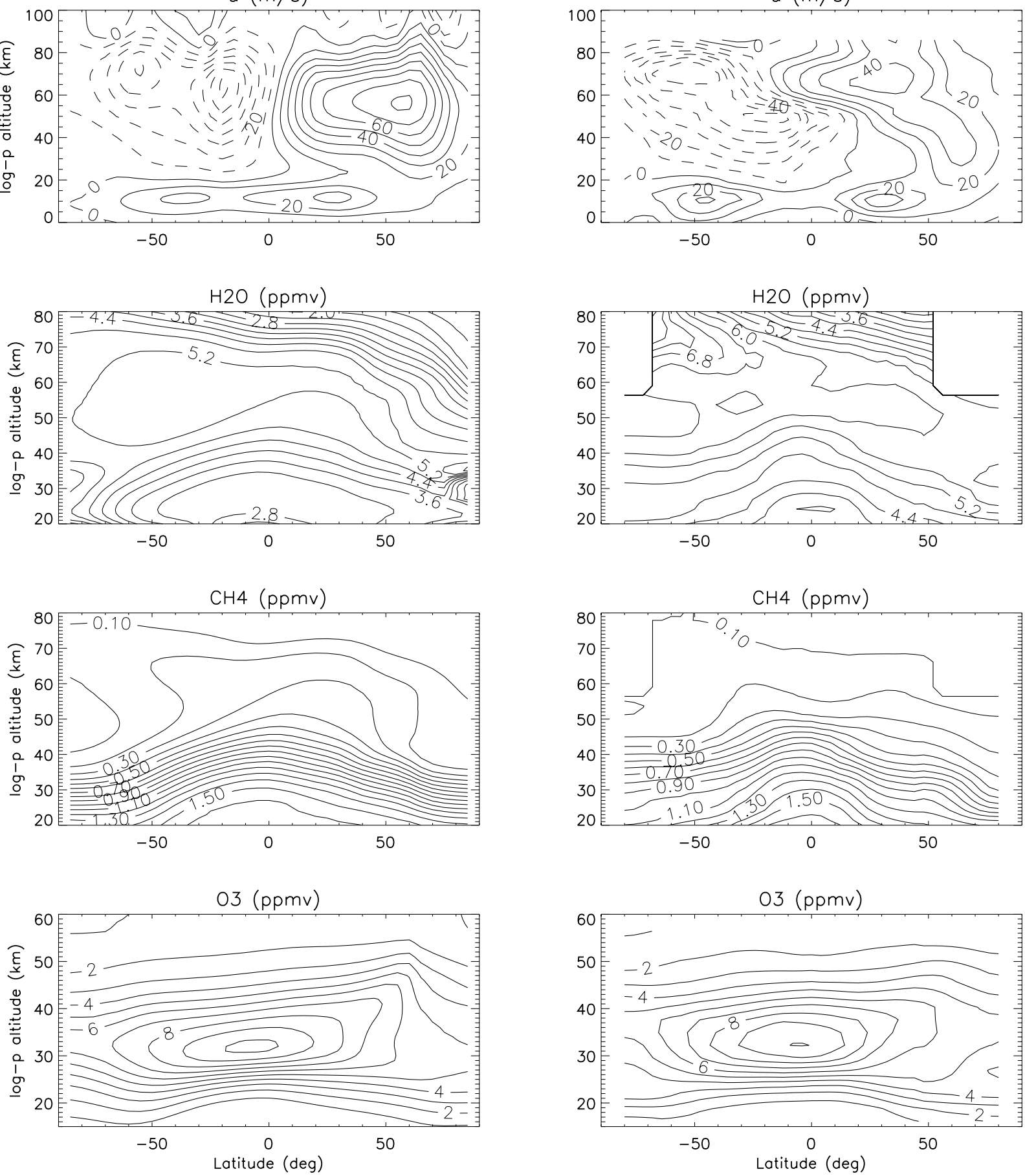
atures [Yulaeva et al., 1994] creates a corresponding cycle in the water vapor that enters the stratosphere over the equator. The minimum occurs during the Northern Hemisphere $(\mathrm{NH})$ winter, and the maximum occurs during the $\mathrm{NH}$ summer. This cycle is preserved as the parcels ascend in the tropical lower stratosphere, creating the so-called "tape recorder" effect [Mote et al., 1996], which can be used to evaluate a model's treatment of water vapor transport in this region. The tape recorder effect for the SOCRATES' baseline atmosphere is presented in Figure $7 \mathrm{a}$, which shows that the model calculates the transport of water vapor into the stratosphere and its seasonal variation $(\sim 1 \mathrm{ppmv}$ at the equatorial tropopause) reasonably well. As will be discussed in sections 5.1 and 5.2, this transport process increases the abundance of water vapor in the stratosphere, and hence in the mesosphere (by the general circulation), in response to an increase in $\mathrm{CO}_{2}$ concentration.

[38] It can be seen from this comparison that the model captures the important features of the observed climatologies well, both qualitatively and quantitatively. Most of the discrepancies between the model calculations and the observed fields are within the uncertainties of the measurements (e.g., 17-20\% for $\mathrm{H}_{2} \mathrm{O}$ [Harries et al., 1996], $11-$ $6 \%$ for $\mathrm{CH}_{4}$ [Park et al., 1996], and 12-6\% for O3 [Brühl et al., 1996], corresponding to the altitude range of 30-60 $\mathrm{km})$. Therefore, the unperturbed state of the atmosphere as simulated by the model agrees well with the observed state, so that the model is suitable for studying climate change in the middle atmosphere.

\section{Description of the Perturbation Scenarios}

[39] The three perturbations that were simulated in this study are the increase in the concentration of greenhouse gases from the preindustrial era to the present, doubled $\mathrm{CO}_{2}$ concentration in an otherwise present day atmosphere, and the 11-year variability in the solar UV irradiance. The specific model modifications for each scenario are described in the following sections. For each case, the appropriate initial and boundary conditions for the relevant species and/ or temperature were specified and 10-year simulations were performed (maintaining the perturbed conditions). The results of the baseline case (present day atmosphere, average solar irradiance, run for 10 years also) were analyzed for attainment of equilibrium conditions in the dynamical and chemical fields in the stratosphere and mesosphere. Equilibrium condition is reached after integrating for no longer than about 6 years (depending on lifetime, latitude, and altitude) in the mesosphere, and in many cases it is reached after about three years. The results presented here are from the last year of the10-year simulations.

\subsection{Increase in the Concentration of the Greenhouse Gases Since the Preindustrial Era}

[40] To simulate preindustrial conditions, we set the surface boundary conditions on $\mathrm{CH}_{4}, \mathrm{~N}_{2} \mathrm{O}, \mathrm{CO}_{2}$, and CFCs to
790 ppbv, 288 ppbv, 280 ppmv, and 0, respectively, consistent with values given by the Intergovernmental Panel on Climate Change [1995] (IPCC) assessment. The initial concentrations of these gases were also adjusted in the same manner at the surface as well as throughout the rest of the model domain. In addition, the surface boundary condition on temperature was adjusted by assuming a cooling of $0.1 \mathrm{~K}$ at the equator which increases linearly to 1.0 and $0.8 \mathrm{~K}$ at the winter and summer poles, respectively, and which increases to $0.6 \mathrm{~K}$ at both poles during the equinox seasons, consistent with the IPCC [1995] assessment.

\subsection{Doubled $\mathrm{CO}_{2}$}

[41] For this scenario, the $\mathrm{CO}_{2}$ boundary condition at the surface (350 ppmv at the equator) and the initial conditions at all points in the spatial domain of the model were doubled. The surface boundary condition on temperature was also adjusted (increased) to simulate the warming caused by doubling $\mathrm{CO}_{2}$. We used the temperature change values obtained by the GISS model (available at www.giss. nasa.gov) as a function of latitude and season.

\subsection{Solar UV Flux Variation}

[42] To simulate solar minimum conditions, we used a solar flux spectrum corresponding to the minimum phase of solar activity that was derived by applying the fractional change values of the solar flux ((Max-Min)/Min) to the average flux data described in section 3.1.1. The fractional change values (G. Rottman, personal communication, 1995) are based on SOLSTICE data and range from 0.70 at 121.6 $\mathrm{nm}($ Lyman- $\alpha)$, to 0.05 at $205 \mathrm{~nm}$. The temperature, $\mathrm{O}\left({ }^{3} \mathrm{P}\right)$, $\mathrm{H}$, and $\mathrm{N}$ distributions at the top boundary of the model $(120 \mathrm{~km})$ were constrained to the profiles calculated by the Mass-Spectrometer-Incoherent-Scatter (MSIS) model (available at http://nssdc.gsfc.nasa.gov/space/model/atmos/ msis.html) for 1986 (minimum phase of solar cycle 21) as functions of latitude and season. In addition, we used the nitric oxide climatology provided by Siskind et al. [1998; Tables $1 \mathrm{a}-1 \mathrm{~b}]$ to constrain the NO concentration at the top boundary. These data, which are derived from measurements by the Solar Mesosphere Explorer (SME) [Barth et al., 1983] and the Halogen Occultation Experiment (HALOE) [Russell et al., 1993], provide NO concentrations as a function of altitude and latitude during the minimum phase of the solar cycle at both high and low auroral activity levels. The data were averaged over auroral activity and interpolated to the model grids to obtain the NO boundary conditions at $120 \mathrm{~km}$.

[43] Similarly, to simulate solar maximum conditions, we used a corresponding solar flux spectrum derived from SOLSTICE data as described above and constrained the temperature, $\mathrm{O}\left({ }^{3} \mathrm{P}\right), \mathrm{H}$, and $\mathrm{N}$ profiles at the top model boundary to those calculated by the MSIS model for 1989 (maximum phase of solar cycle 21). Also, in the same manner as described above, the boundary condition on NO concentration was obtained from Siskind's climatology

Figure 1. (opposite) Baseline model profiles of temperature $(\mathrm{K})$, zonal wind $(\mathrm{m} / \mathrm{s})$, and mixing ratios (ppmv) of water vapor, methane, and ozone for January (left panels), compared with the corresponding observed climatologies (right panels). Measured data are from CIRA for temperature and zonal wind and from the UARS Reference Atmosphere Project for $\mathrm{H}_{2} \mathrm{O}, \mathrm{CH}_{4}$, and $\mathrm{O}_{3}$; contour levels are $10 \mathrm{~K}, 10 \mathrm{~m} / \mathrm{s}, 0.4$ ppmv, $0.1 \mathrm{ppmv}$, and 1 ppmv, respectively. 

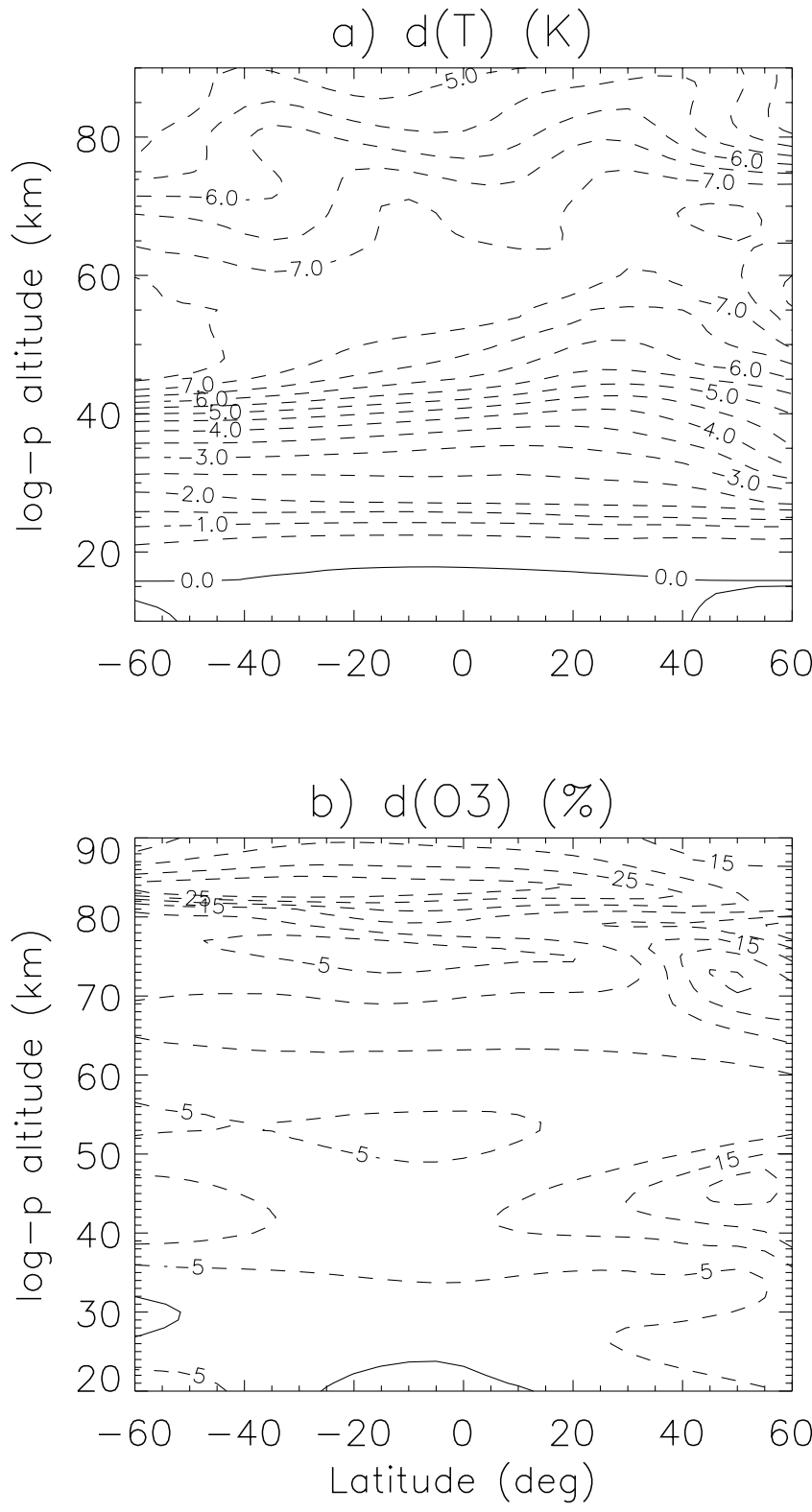

Figure 2. Response of the mesosphere to the increase in the concentration of greenhouse gases from the preindustrial era (present-preindustrial) for January: (a) absolute change in temperature $(\mathrm{K})$ and $(\mathrm{b})$ percent change in ozone mixing ratio; contour intervals are $0.5 \mathrm{~K}$ and $5 \%$, respectively, and dashed lines indicate negative change, i.e., lower values for the present-day atmosphere relative to the preindustrial one.

(Tables 1c and 1d of Siskind et al. [1998] for high solar, high/low auroral activity).

\section{Results and Discussion}

\subsection{Increase in Concentration of Greenhouse Gases} Since the Preindustrial Era

[44] The model predictions of the changes in temperature and $\mathrm{O}_{3}$ mixing ratio due to increased anthropogenic emissions of radiatively active ("greenhouse") gases from their preindustrial levels to the present are shown in Figure 2. As expected, because of increased IR emission to space, which is primarily due to the increase in $\mathrm{CO}_{2}$ abundance, and because of decrease in ozone (discussed below), the mesosphere has cooled by 5-9 K. The largest cooling occurs in the separated stratopause region at high-latitude winter in the lower mesosphere (partly because of the strong dependence of infrared emission on temperature and partly due to weaker downward circulation (not shown)). In contrast, the cooling near the summer mesopause region, where temperature is the coldest, is about $4 \mathrm{~K}$. Note also that the model troposphere has warmed up. In particular, consistent with previous studies [e.g., Rind et al., 1990], the tropical tropopause temperature has increased by about $0.1 \mathrm{~K}$, which is large enough to allow more water vapor to penetrate into the stratosphere (discussed below).

[45] The cooling affects the rate of chemical reactions involving the odd hydrogen $\left(\mathrm{HO}_{\mathrm{x}}\right)$ and odd oxygen species $\left(\mathrm{O}_{\mathrm{x}}\right)$. For example, the loss of ozone through reaction with atomic oxygen $\left(\mathrm{O}+\mathrm{O}_{3} \rightarrow 2 \mathrm{O}_{2}\right)$, whose rate coefficient is strongly correlated with temperature, is expected to decrease, leading to enhanced abundance of mesospheric ozone. However, the net change is a decrease in ozone mixing ratio (Figure $2 \mathrm{~b}$ ) in most of the mesosphere (discussed below) from about 5\% just above the stratopause to about $30 \%$ near $85 \mathrm{~km}$ from $60^{\circ} \mathrm{S}$ to $20^{\circ} \mathrm{N}$. Note also that the calculated decrease in the upper stratospheric ozone abundance is consistent with the recent assessments of the observed trends [e.g., WMO, 1998].

[46] Figure $2 \mathrm{~b}$ represents the change in the diurnally averaged mixing ratio of ozone, which can be better understood by analyzing the change in its diurnal production and loss mechanisms. The response in the diurnal mixing ratios of the $\mathrm{HO}_{\mathrm{x}}$ and $\mathrm{O}_{\mathrm{x}}$ species that are involved in the photochemical equilibrium of $\mathrm{O}_{3}$ in the mesosphere is shown in Figure 3. Figures $3 \mathrm{a}$ and $3 \mathrm{~b}$ show that the abundance of $\mathrm{O}\left({ }^{3} \mathrm{P}\right)$ decreases in most of the mesosphere both at noon and at midnight, which reduces the production of ozone $\left(\mathrm{O}+\mathrm{O}_{2}+\mathrm{M} \rightarrow \mathrm{O}_{3}+\mathrm{M}\right)$ throughout the day. Figures $3 \mathrm{c}$ and $3 \mathrm{~d}$ show the change in the mixing ratio of $\mathrm{OH}$ at noon and midnight, respectively, and Figures $3 \mathrm{e}$ and $3 \mathrm{f}$ are the corresponding figures for atomic hydrogen. Clearly, both $\mathrm{OH}$ and $\mathrm{H}$, which provide the main loss mechanisms of ozone in the mesosphere, show a complicated response to the increase in the concentration of the greenhouse gases. The $\mathrm{OH}$ abundance increases substantially in most of the mesosphere at noon and near the mesopause region at night, but it decreases greatly below about $80 \mathrm{~km}$ at night. The mixing ratio of $\mathrm{H}$ increases modestly at noon near the tropical mesopause region, but it decreases substantially at night in the mid to upper mesosphere.

[47] The combined effects of these changes in $\mathrm{OH}$ and $\mathrm{H}$ are presented in Figures $3 \mathrm{~g}$ and $3 \mathrm{~h}$, which show the response of ozone at noon and at midnight, respectively. Clearly, ozone has decreased in most of the mesosphere both at noon and at night. The small increase in $\mathrm{O}_{3}$ near 80 $\mathrm{km}$ at night is a result of the very large decrease in the odd oxygen loss through $\mathrm{OH}$ and $\mathrm{H}$.

[48] The substantial increase in the $\mathrm{OH}$ abundance is due to the increase in water vapor $\left(\mathrm{H}_{2} \mathrm{O}+\mathrm{h} \nu \rightarrow \mathrm{OH}+\mathrm{H}\right)$. As shown in Figure $4 \mathrm{a}$, the $\mathrm{H}_{2} \mathrm{O}$ mixing ratio increases by $\sim 40 \%$ in the lower mesosphere and by $\sim 60 \%$ near the 

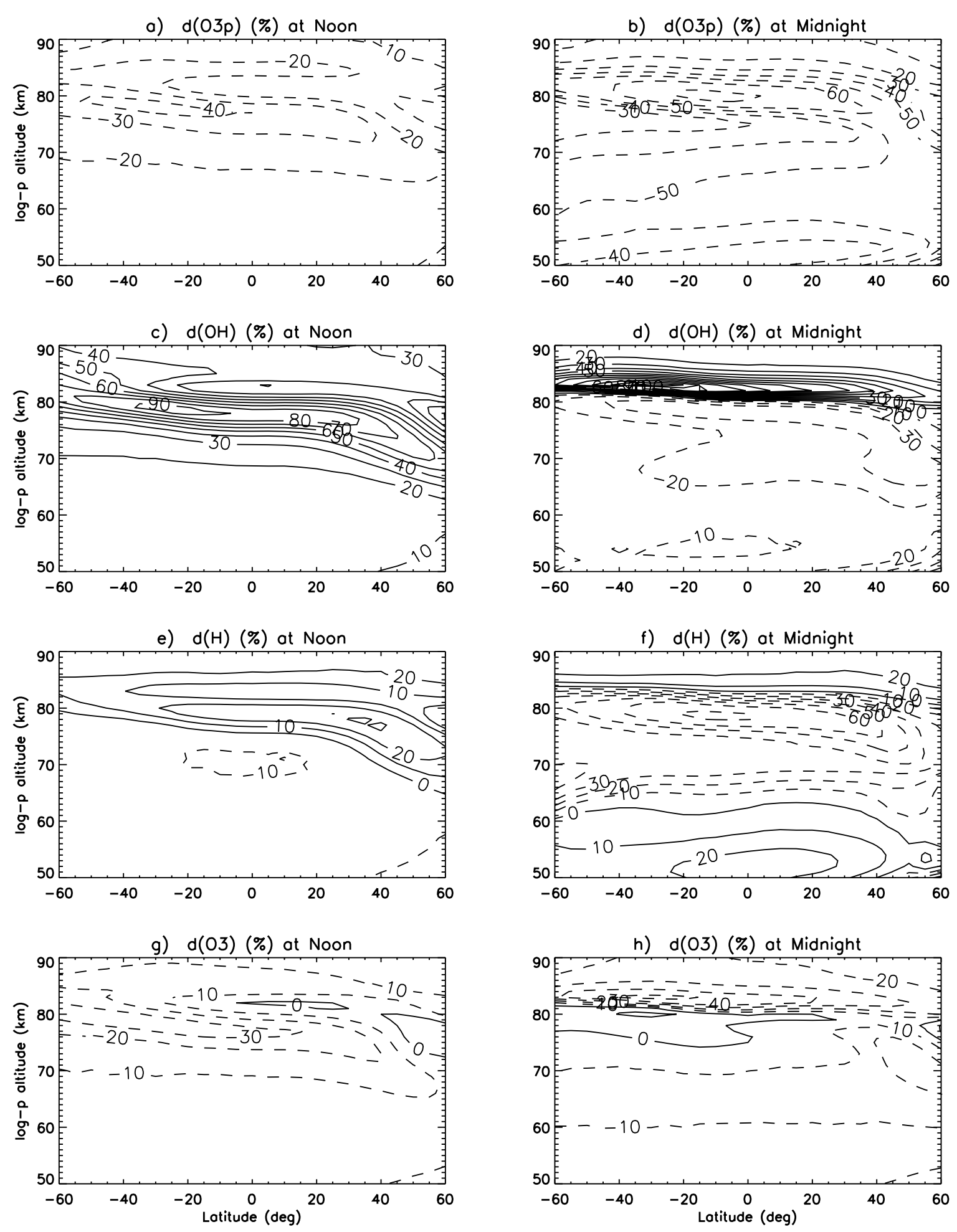

h) $d(03)(\%)$ at Midnight

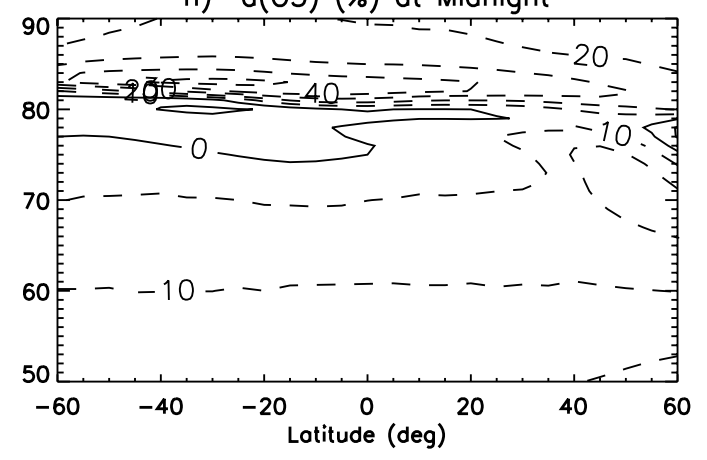

Figure 3. Diurnal response in mixing ratios of $\mathrm{HO}_{\mathrm{x}}$ and $\mathrm{O}_{\mathrm{x}}$ species in mesosphere to increase in concentration of greenhouse gases from preindustrial era to present (for January). Changes at noon are shown in the left-hand panels and those at midnight in the right-hand panels. Contour interval for all panels is $10 \%$, and, as in Figure 2, dashed contours indicate lower values for present-day atmosphere relative to preindustrial one.

mesopause region (where the increase in $\mathrm{OH}$ mixing ratio is maximum). The enhancement in the mesospheric water vapor, which is transported from the stratosphere, is a consequence of the increase in methane $\left(\mathrm{CH}_{4}+\mathrm{OH} \rightarrow\right.$
$\mathrm{H}_{2} \mathrm{O}+\mathrm{CH}_{3}$ ) and to a lesser extent in $\mathrm{CO}_{2}$ (warming of the tropical tropopause, Figure $2 \mathrm{a}$ ). This can be seen from the change in water vapor distributions obtained from two quasi-preindustrial simulations. In one case, the mixing 
a) $\mathrm{d}(\mathrm{H} 2 \mathrm{O})(\%)$; Pres-Preind

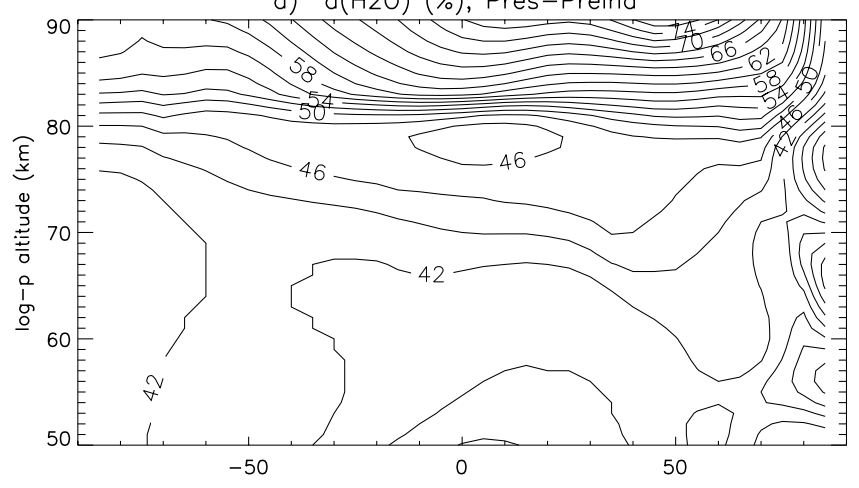

b) $\mathrm{d}(\mathrm{H} 2 \mathrm{O})(\%)$; Preind Except $\mathrm{CH} 4$ - Preind

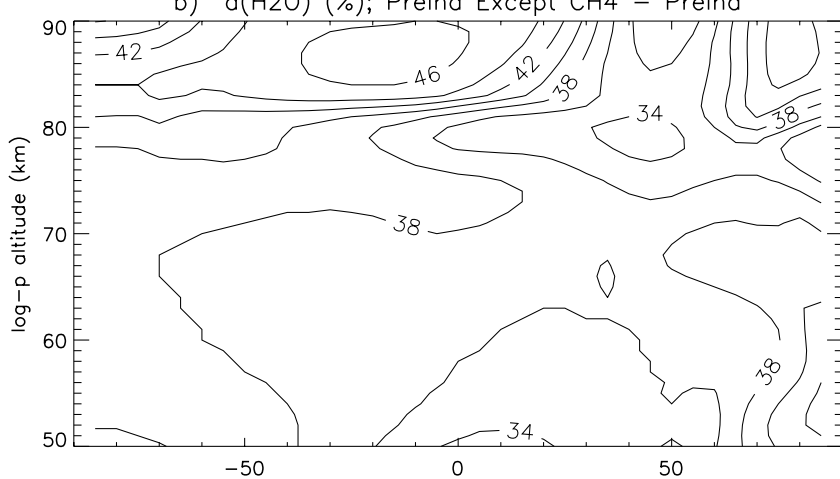

c) $\mathrm{d}(\mathrm{H} 2 \mathrm{O})(\%)$; Preind Except $\mathrm{CO} 2$ - Preind

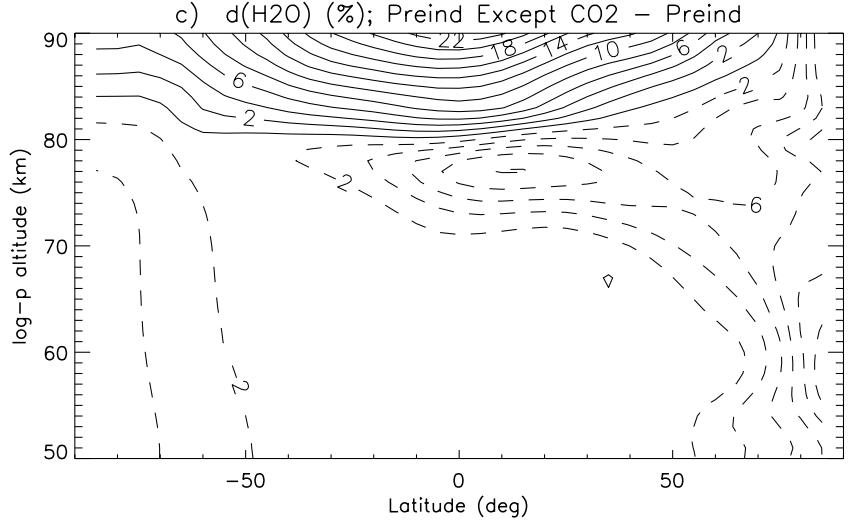

Figure 4. (a) Increase in water vapor abundance due to increase in concentration of all greenhouse gases from their preindustrial levels to present; (b) effect of increase in concentration of methane alone (from preindustrial to present) on water vapor when all other greenhouse gases remain at their preindustrial levels; (c) effect of increase in concentration of $\mathrm{CO}_{2}$ alone (from preindustrial to present) on water vapor when all other greenhouse gases remain at their preindustrial levels; results are for January.

ratio of methane alone is maintained at the present day levels while the mixing ratios of the other greenhouse gases are kept at their preindustrial levels. In the second case, only the $\mathrm{CO}_{2}$ mixing ratio is kept at the present day level, with the abundance of the other greenhouse gases at their preindustrial levels. The resulting changes in the water vapor distributions from these two cases relative to the full preindustrial case are shown in Figures $4 b$ and $4 c$, respectively. Comparison of Figures $4 \mathrm{~b}$ and $4 \mathrm{c}$ with Figure $4 \mathrm{a}$ shows that the increase in $\mathrm{CH}_{4}$ is the dominant cause of the enhanced water vapor mixing ratios throughout the mesosphere. Above $80 \mathrm{~km}$, however, larger $\mathrm{K}_{\mathrm{zz}}$ values, which result from changes in gravity wave breaking conditions in a cooler mesosphere (see Figure 8b), increase the vertical mixing of $\mathrm{H}_{2} \mathrm{O}$ in a region where the vertical gradient in its mixing ratio is large.

\subsection{Impact of Doubling $\mathrm{CO}_{2}$ Concentration}

[49] Figure 5a shows the calculated change in the temperature structure of the mesosphere when $\left[\mathrm{CO}_{2}\right]$ is doubled. Substantial cooling $(5-16 \mathrm{~K})$ occurs throughout the mesosphere, initiated by enhanced thermal emission due to the increased $\mathrm{CO}_{2}$ abundance. The temperature response is not, however, entirely due to radiative processes. As shown in Figure $5 \mathrm{~b}$, the net radiative heating rate (solar + chemical heating rates - terrestrial cooling rate) increases by up to $\sim 0.4 \mathrm{~K} /$ day in the high-latitude summer mesopause region, but the temperature there decreases by up to $6 \mathrm{~K}$ (Figure 5a). As shown in Figure 5c, the change in the vertical velocity is very similar to that in the net radiative heating rate. This is because at steady state, the change in the net radiative heating rate must be compensated by an equivalent change in the adiabatic (dynamical) heating rate. The response of the meridional circulation is characterized by a stronger upward motion in the summer mesosphere above $70 \mathrm{~km}$, leading to increased adiabatic cooling. Therefore dynamical feedbacks cause an overall cooling in this region. This is consistent with the results of Portmann et al. [1995], who calculated the radiative-only response in temperature by keeping the advective and diffusive heating terms at their baseline $\left(1 \times \mathrm{CO}_{2}\right)$ values, which resulted in a large warming of up to $14 \mathrm{~K}$ in the summer mesopause region. Thus, the net thermal response of the mesosphere is affected significantly by dynamical feedbacks.

[50] The change in the total heating component of the thermal response, which is the sum of solar and chemical heating, is shown in Figure 5d. Because the ozone abundance increases in most regions in the mesosphere (Figure 6a), there is a corresponding increase in the total heating rate of $\sim 1 \mathrm{~K} /$ day in the lower mesosphere to $\sim 0.1 \mathrm{~K} /$ day at $70 \mathrm{~km}$. Near and above $80 \mathrm{~km}$, the response of the total heating rate is dominated by the change in chemical heating (Figure 5e), with a small contribution from the change in ozone.

[51] Doubling the $\mathrm{CO}_{2}$ mixing ratio also affects the chemical composition of the mesosphere (Figure 6). These results are presented in terms of diurnal averages, which capture the important features of the effect during both day and night. As shown in Figure 6a, the response of ozone is not uniform. A substantial decrease of up to about $25 \%$ occurs near the high-latitude summer mesopause region, whereas it increases by up to $15 \%$ between 70 and $80 \mathrm{~km}$, decreases by a few percent between 65 and $70 \mathrm{~km}$, and increases by up to $20 \%$ in the lower mesosphere. This complicated response, which is present in both the day and night profiles of the change in ozone (not shown), can be traced to the changes in the abundance of the odd hydrogen species, $\mathrm{OH}$ and $\mathrm{H}$. As shown in Figure $6 \mathrm{~b}$, the large increase in $\mathrm{OH}$ near the mesopause region causes the substantial decrease of ozone there. Decrease in atomic hydrogen (Figure 6c), whose rate of reaction with ozone 

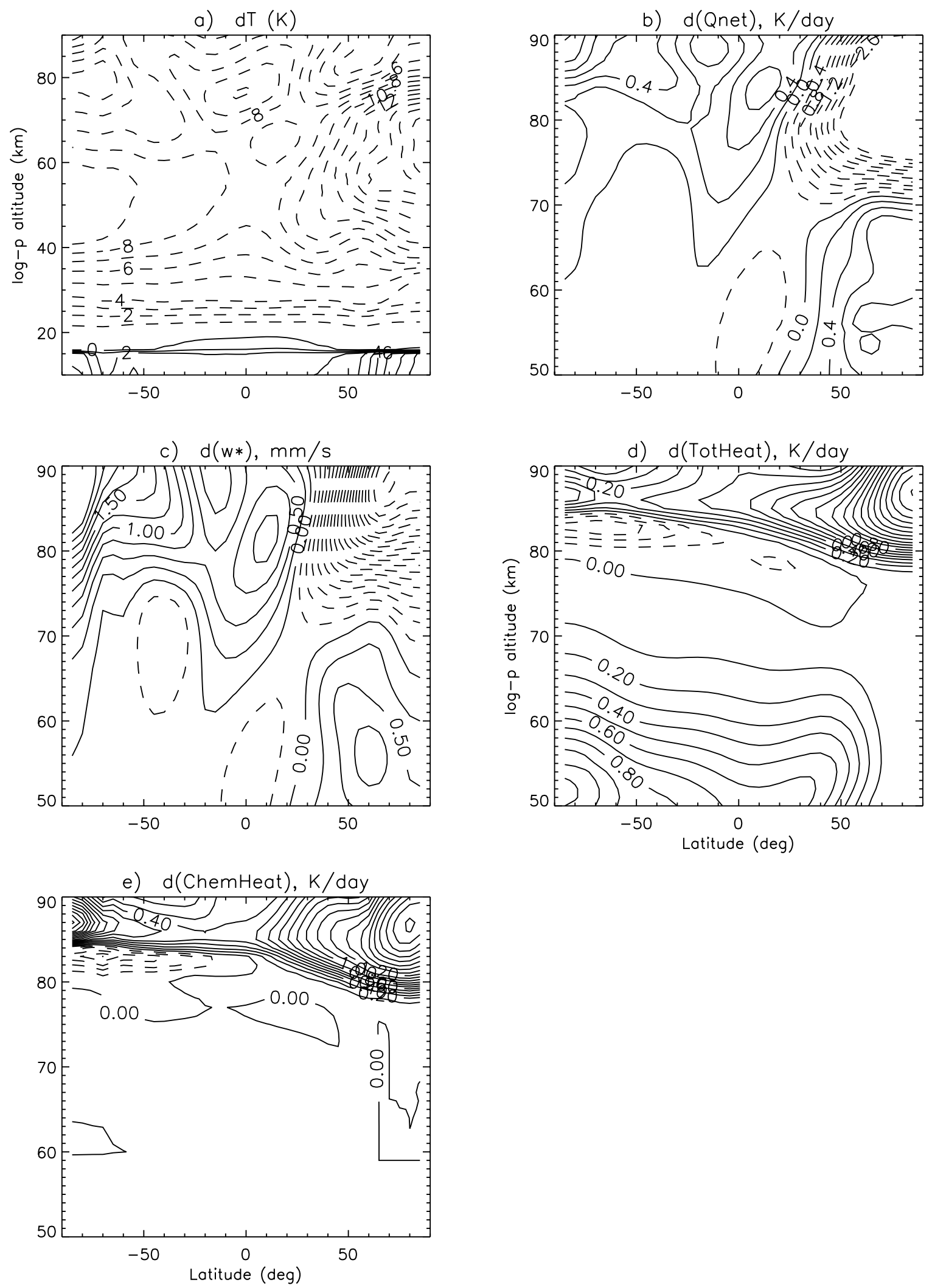

Figure 5. Thermal response of mesosphere to doubling $\mathrm{CO}_{2}$ : (a) temperature $(\mathrm{K})$, (b) net heating rate (total heating rate - total cooling rate; K/day), (c) vertical velocity $\left(\overline{w^{*}} ; \mathrm{mm} / \mathrm{s}\right)$, (d) total heating rate (solar plus chemical, $\mathrm{K} /$ day), and (e) chemical heating rate (K/day). All changes are in absolute terms and are shown relative to present-day baseline atmosphere $\left(2 \times \mathrm{CO}_{2}-1 \times \mathrm{CO}_{2}\right)$ so that negative values (dashed contours) indicate a decrease due to doubling the $\mathrm{CO}_{2}$ concentration. Contour intervals are $1 \mathrm{~K}, 0.2 \mathrm{~K} /$ day, $0.25 \mathrm{~mm} / \mathrm{s}, 0.1 \mathrm{~K} /$ day, and $0.2 \mathrm{~K} /$ day for Figures $5 \mathrm{a}-5 \mathrm{e}$, respectively, and the results are for January. 

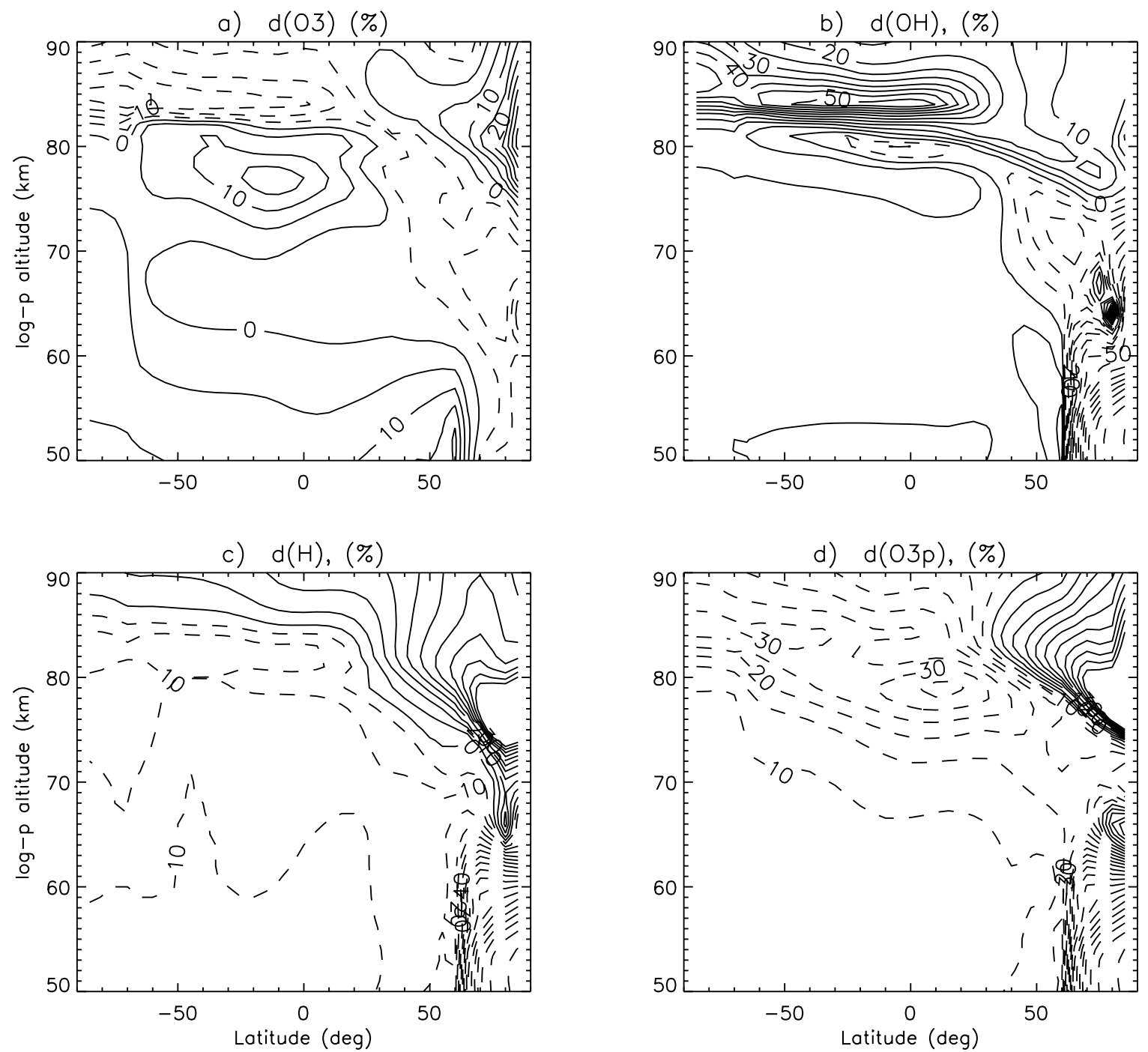

Figure 6. Chemical response of mesosphere to doubling $\mathrm{CO}_{2}$ (January). All changes are relative to present-day baseline atmosphere $\left(2 \times \mathrm{CO}_{2}-1 \times \mathrm{CO}_{2}\right)$ so that negative values (dashed contours) indicate a decrease due to doubling the $\mathrm{CO}_{2}$ concentration. Contour intervals are $5 \%$.

is about 2 orders of magnitude faster than that of $\mathrm{OH}+\mathrm{O}_{3}$, causes the ozone increase seen in the summer hemisphere. Although the abundances of $\mathrm{H}$ and $\mathrm{OH}$ decrease in the high latitude winter mesosphere at altitudes up to about $70 \mathrm{~km}$, the reduced production of ozone due to the very large decrease in atomic oxygen abundance (Figure 6d) becomes dominant and causes the corresponding decrease seen in Figure 6a.

[52] The change in the chemistry of $\mathrm{HO}_{\mathrm{x}}$ in this scenario is similar to the change since the preindustrial era (section 5.1). Namely, because of a large increase in the mixing ratio of water vapor in the upper mesosphere, the $\mathrm{OH}$ abundance increases dramatically in this region. As in the preindustrial case, one cause of the increase in the water vapor mixing ratio is the warming of the tropical tropopause. Figure 5a shows that when the $\mathrm{CO}_{2}$ mixing ratio is doubled, temperature increases by $\sim 1 \mathrm{~K}$ at $16 \mathrm{~km}$ over the equator, which increases the saturation vapor pressure of water, allowing more water vapor to be transported into the stratosphere. This can be seen in Figure 7, which compares the tape recorder effect (see section 3.4) for the $2 \times \mathrm{CO}_{2}$ case (Figure 7b) with that for the baseline atmosphere (Figure 7a). It is clear that more water vapor has penetrated into the equatorial lower stratosphere in response to the increase in $\mathrm{CO}_{2}$ concentration. Furthermore, Figure $7 \mathrm{c}$ shows that the seasonal variation in the equatorial tropopause temperature is preserved when $\mathrm{CO} 2$ mixing ratio is doubled, hence preserving the corresponding seasonal cycle in the water vapor mixing ratio (Figure $7 \mathrm{~d}$ ), which has increased by $\sim 38 \%$ in the equatorial tropopause.

[53] The map of the global change in the water vapor mixing ratio in the stratosphere and mesosphere is shown in Figure 8 . The large increase in the winter mesopause region is associated with the enhanced levels of the vertical eddy diffusion coefficient, $\mathrm{K}_{\mathrm{zz}}$ (Figure 8b), which increases the vertical mixing of water molecules. This effect is substantial above $80 \mathrm{~km}$, where the $\mathrm{H}_{2} \mathrm{O}$ mixing ratio decreases rapidly with altitude. Another cause of the increase in the water vapor abundance is the substantial increase in methane in the upper mesosphere (Figure 8c), which is dynamical in 
a) $\mathrm{H} 2 \mathrm{O}$ (ppmv), Equator, Baseline

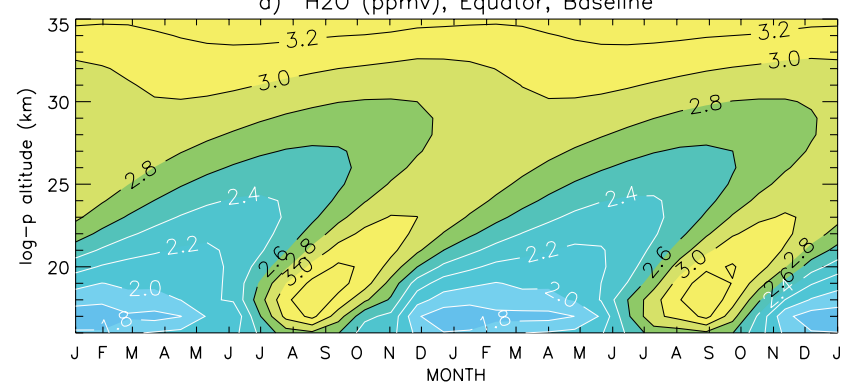

b) $\mathrm{H} 2 \mathrm{O}$ (ppmv), Equator, $2 \times \mathrm{CO} 2$

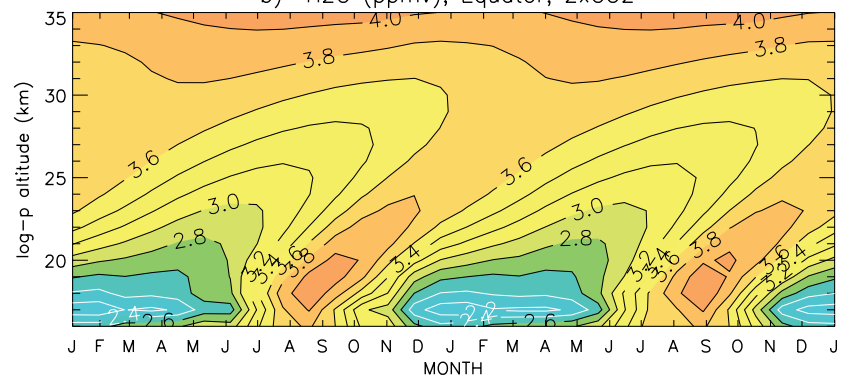

c) $T$ at $16 \mathrm{~km}$, Equator

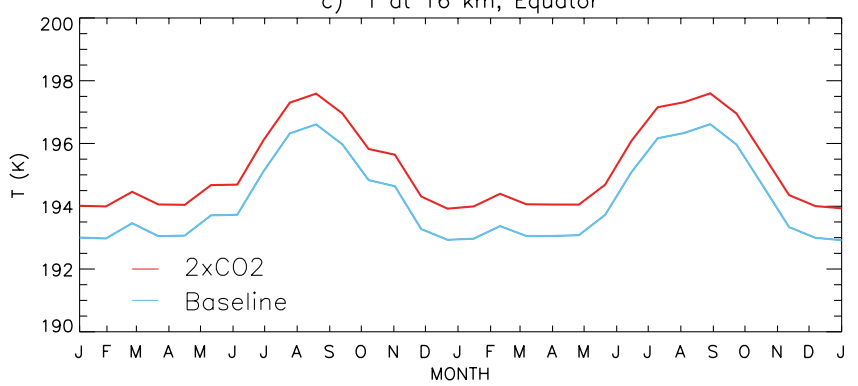

d) $\mathrm{H} 2 \mathrm{O}$ at $16 \mathrm{~km}$, Equator

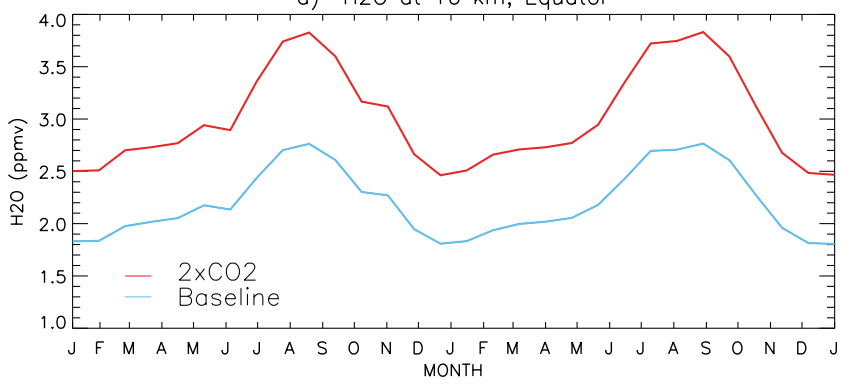

Figure 7. Calculated tape recorder effect for water vapor at the equator for (a) baseline model atmosphere and (b) doubled $\mathrm{CO}_{2}$ atmosphere. In both panels the contour intervals are $0.2 \mathrm{ppmv}$ and the same color scale is used. (c) Seasonal variation of temperature at the equatorial tropopause for baseline (blue) and doubled $\mathrm{CO}_{2}$ (red). (d) Corresponding variation in water vapor mixing ratio. Note that the equatorial tropopause temperature warms up by about $1 \mathrm{~K}$ throughout the year in response to doubling the $\mathrm{CO}_{2}$ mixing ratio, and that as a result, the water vapor mixing ratio increases by about $38 \%$ in that region.

nature as indicated by the change in $\mathrm{K}_{\mathrm{zz}}$ associated with changes in momentum deposition by gravity waves.

\subsection{Effects of Variability in Solar UV Flux}

[54] The results of our solar variability simulations are shown in Figures 9 and 10 for the response of the thermal and chemical structure of the mesosphere, respectively. These results are shown in terms of change from solar minimum to solar maximum conditions, which is the reverse of the usual manner in which such calculations are presented. The reason is that it brings out more clearly the similarities and differences (discussed in section 6) between the mesospheric response in these simulations and those in the doubled $\mathrm{CO}_{2}$ scenario.

[55] As expected, the mesosphere cools (by up to $5 \mathrm{~K}$ ) when solar UV flux decreases (Figure 9a). However, our results indicate that this cooling is not entirely a direct
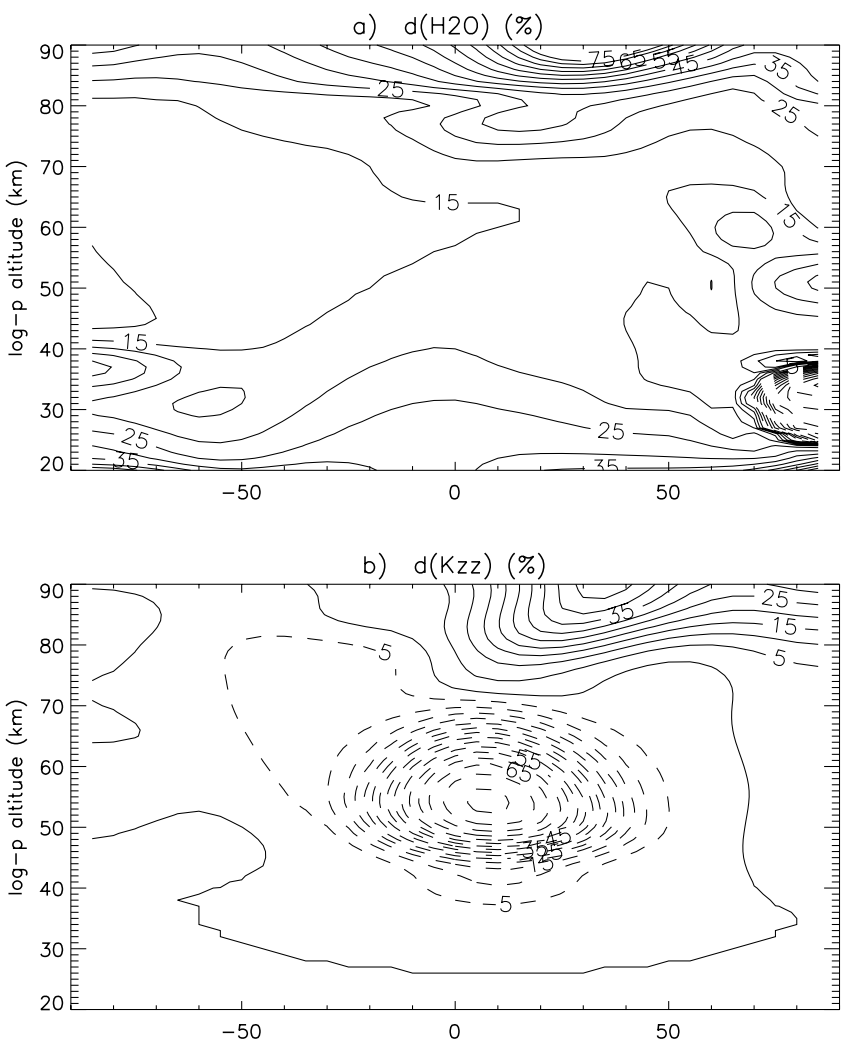

c) $\mathrm{d}(\mathrm{CH} 4)(\%)$

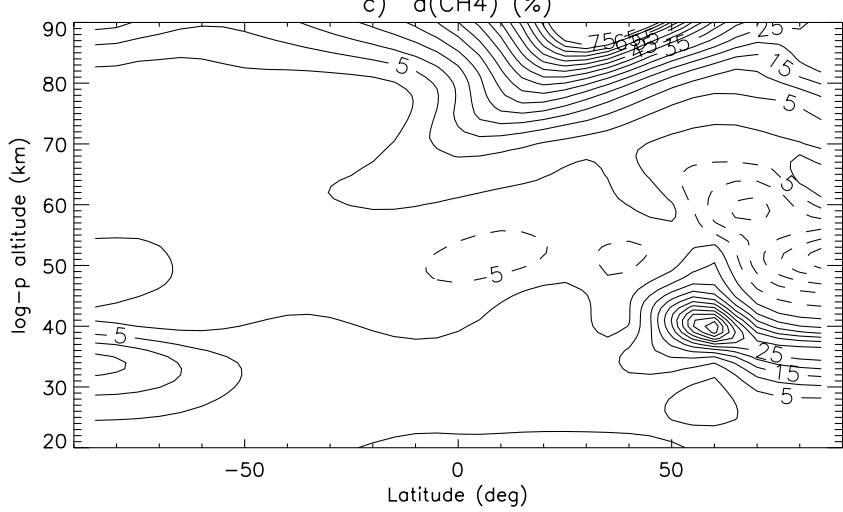

Figure 8. Percent change due to doubling the $\mathrm{CO}_{2}$ abundance in (a) water vapor mixing ratio, (b) vertical eddy diffusivity coefficient $\left(\mathrm{K}_{\mathrm{zz}}\right)$, and (c) methane mixing ratio, relative to the baseline atmosphere $\left(2 \times \mathrm{CO}_{2}-1 \times\right.$ $\mathrm{CO}_{2}$ ) for January. Dashed contours indicate negative values, i.e. a decrease due to doubling the $\mathrm{CO}_{2}$ mixing ratio. Contour intervals are $5 \%$. 

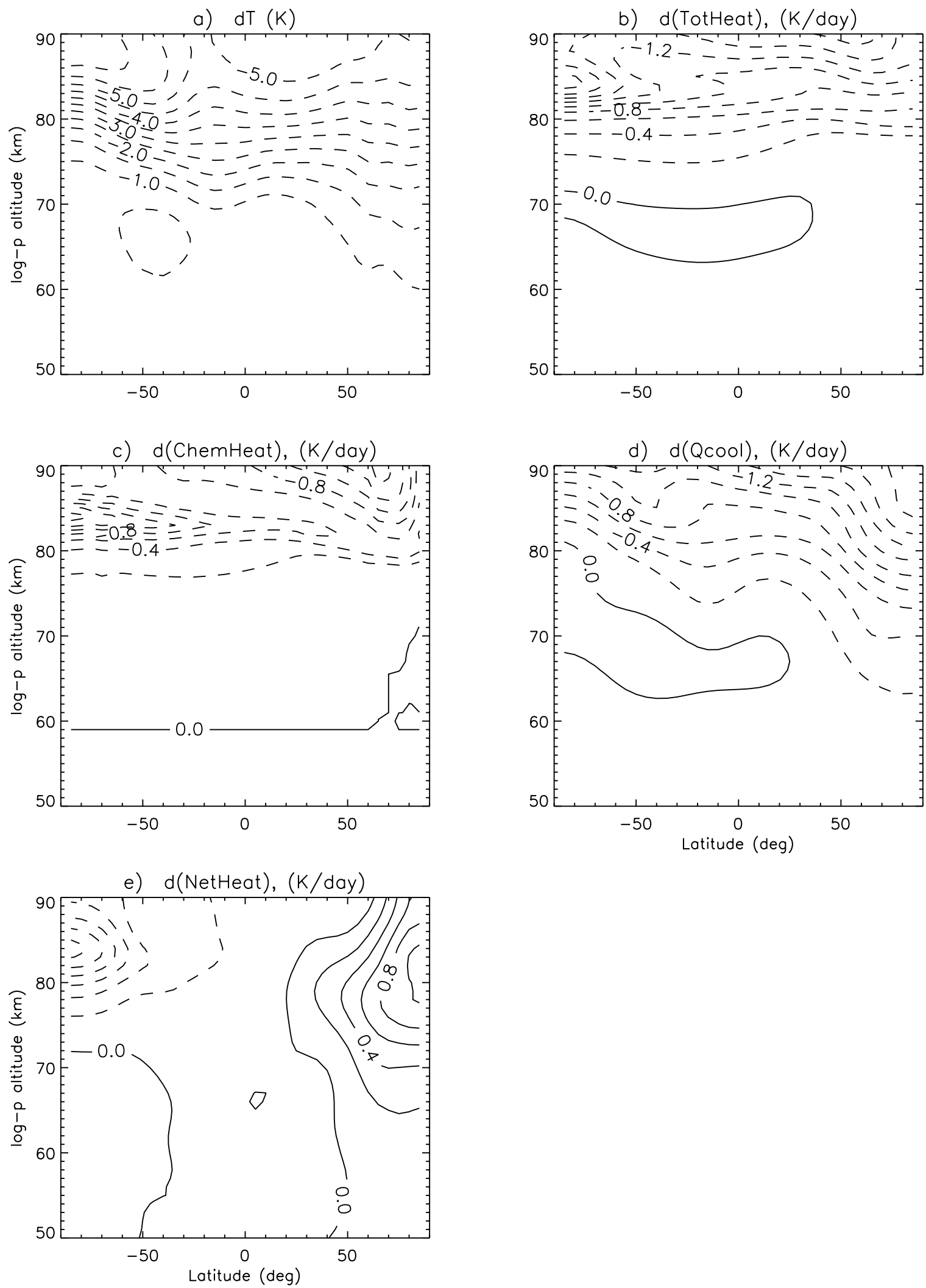

Figure 9. Thermal response of mesosphere due to the 11-year solar cycle in UV flux; (a) temperature, (b) total heating rate which is the sum of chemical and solar heating rates, (c) chemical heating rate, (d) total IR cooling rate, and (e) net heating rate. All changes (Solar Min-Solar Max) are given in absolute terms for January, and dashed contours indicate a decrease in the quantity during solar minimum conditions. Contour intervals are $0.5 \mathrm{~K}$ for the change in temperature and $0.2 \mathrm{~K}$ /day for the changes in heating/cooling rates. 

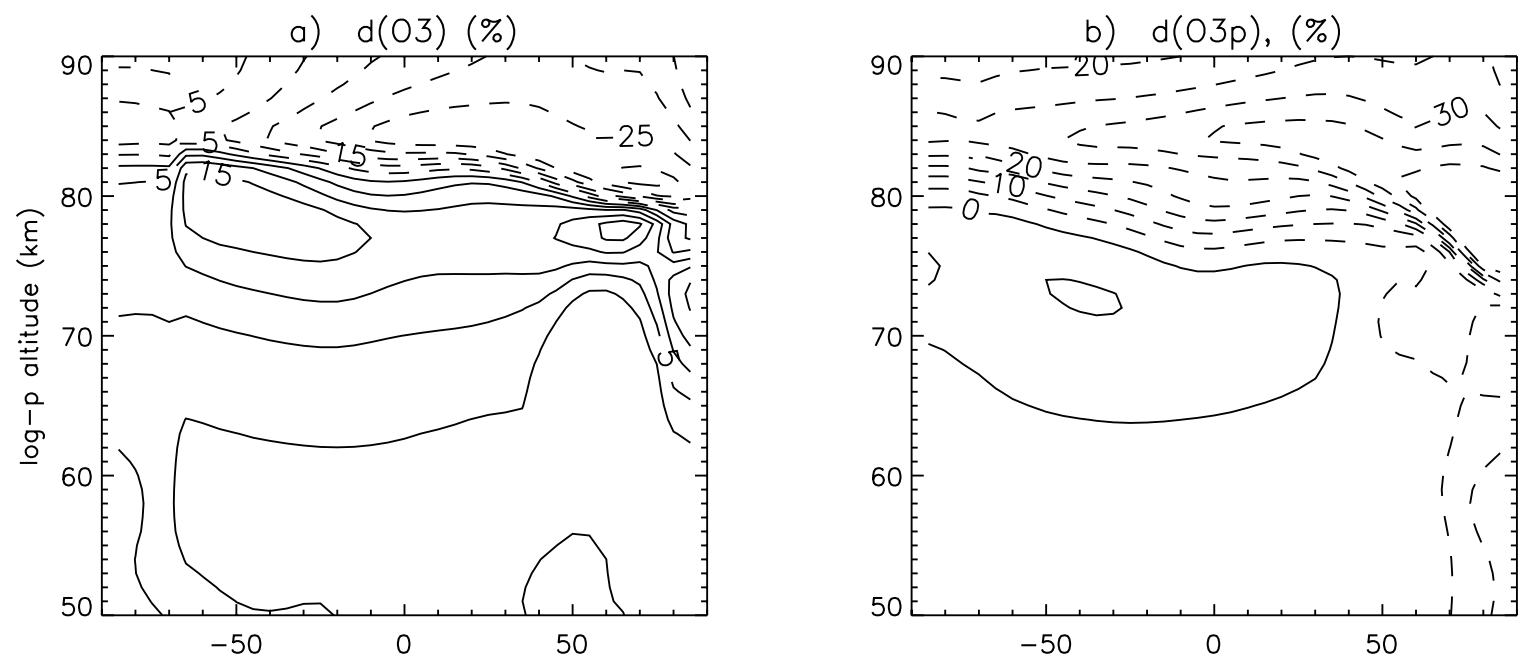

c) $\mathrm{d}(\mathrm{H} 2 \mathrm{O}),(\%)$
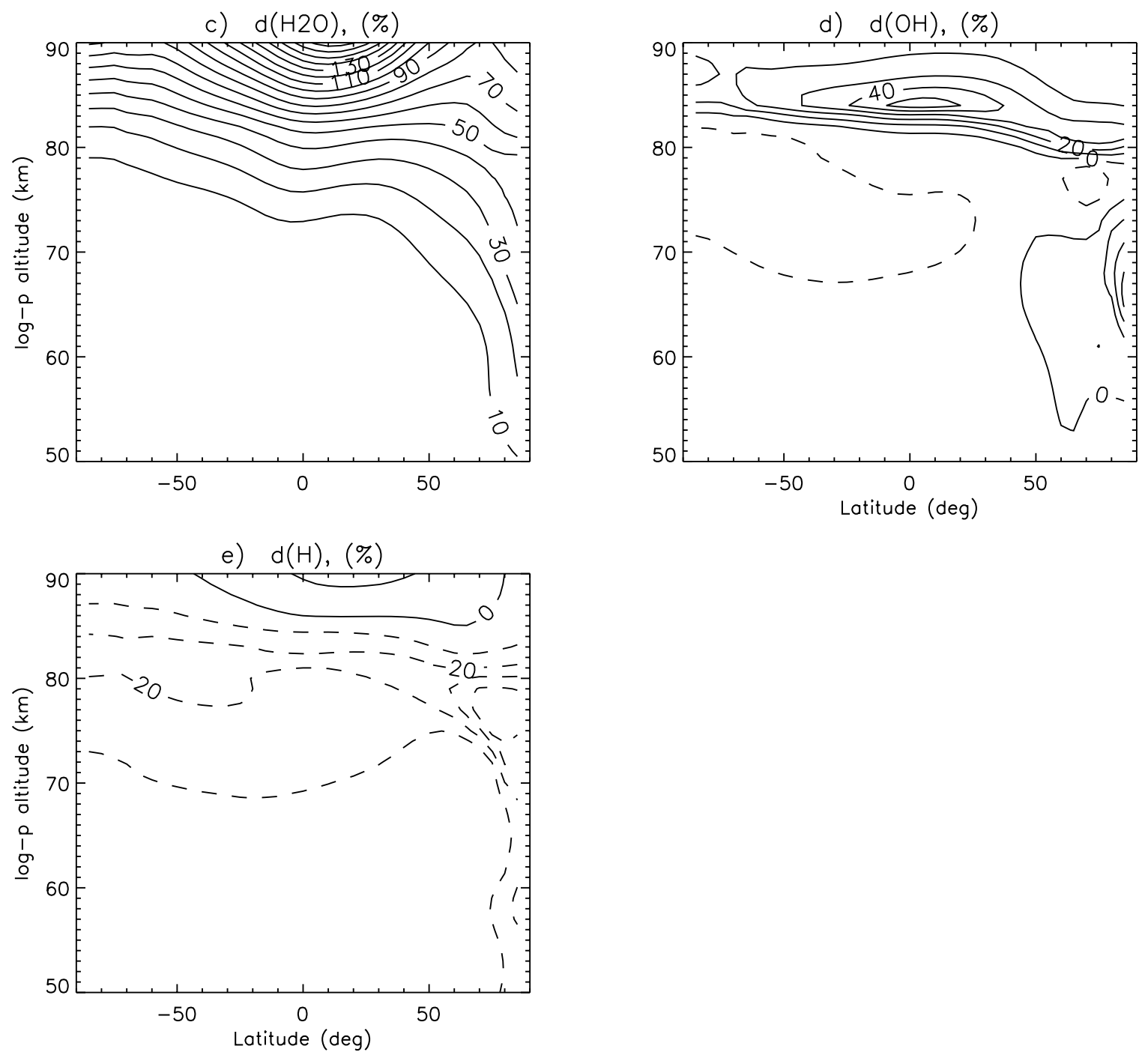

Figure 10. Same as in Figure 9, but for chemical response of mesosphere. Contour intervals are 5\% for $(\mathrm{a}, \mathrm{b})$ and $10 \%$ for $(\mathrm{c}-\mathrm{e})$. 
radiative response (similar to the $2 \times \mathrm{CO}_{2}$ case). Figures $9 b-9 d$ show the changes in the components of the net heating rate in the mesosphere. Clearly, in the lower mesosphere, temperature does not decrease greatly because a decrease in the solar heating rate lowers the temperature, which in turn reduces the cooling, thus maintaining the state of radiative equilibrium. Above $75 \mathrm{~km}$ the changes in the total heating and IR cooling rates become significant, and the decrease in the chemical heating rate makes a large contribution to the change in the total heating rate. However, as Figure 9e shows, the net heating rate, which is the radiative forcing term in the thermodynamic equation, does not change so greatly as to cause the large decreases seen in temperature in the upper mesosphere (Figure 9a). Therefore, dynamical feedbacks, which comprise the other forcing terms in the thermodynamic equation, cause most of the change in temperature above $75 \mathrm{~km}$.

[56] The chemical response of the mesosphere to a reduction in solar UV irradiance is shown in Figure 10. The significant decrease in the abundance of ozone in the mesopause region (Figure 10a) is caused by both a decrease in its production rate and an increase in its loss rate. The decrease in the photolysis rate of molecular oxygen in the Schumann-Runge continuum, which accompanies the transition from solar maximum to solar minimum conditions, substantially reduces the abundance of atomic oxygen (Figure 10b) and hence the production of ozone. Furthermore, the decrease in Lyman- $\alpha$ radiation (which has the largest variability in the solar spectrum) enhances the abundance of water vapor in the upper mesosphere substantially (Figure 10c). For example, the calculated increase is $30-40 \%$ at about $80 \mathrm{~km}$, consistent with the increase calculated from HALOE data by Chandra et al. [1997]. The steady state effect of these two changes in the upper mesosphere is a substantial increase in the mixing ratio of $\mathrm{OH}$ (Figure 10d), which greatly enhances the loss of ozone in this region. We note, however, that ozone loss is moderated by the decrease in atomic hydrogen $\left(\mathrm{O}_{3}+\mathrm{H} \rightarrow \mathrm{OH}+\mathrm{O}_{2}\right)$, which becomes significant in the upper mesosphere (Figure 10e).

[57] Finally, it should be noted that discrepancies between observed and modeled responses of temperature and $\mathrm{O}_{3}$ to the 11-year solar cycle have been reported both in the stratosphere [Brasseur, 1993; McCormak and Hood, 1996] and mesosphere [Summers et al., 1990] at selected latitudes. However, in light of availability of the more global UARS measurements of temperature and constituents over the last decade, a reevaluation of model versus observed responses to the 11-year solar flux variations is indicated.

\section{Comparison of $2 \times \mathrm{CO}_{2}$ and Solar Variability Effects}

[58] The results of our simulations show interesting similarities in the response of the mesosphere to the doubled $\mathrm{CO}_{2}$ and solar variability perturbations. As Figures 5a and 9a illustrate, in both cases the mesosphere cools substantially. However, the structure of the decrease in temperature is strikingly different between the two cases. The latitudinal gradient of the decrease in temperature due to lower solar irradiance is very weak, in contrast to the $2 \times \mathrm{CO}_{2}$ case. In addition, the largest decrease in temperature corresponding to solar minimum conditions occurs in the upper mesosphere, whereas in the doubled $\mathrm{CO}_{2}$ case it occurs in the lower mesosphere (in the winter polar region; see sections 5.2 and 5.3 for details).

[59] There are also remarkable similarities (and differences) in the chemical response of the mesosphere to the two perturbations. As Figures 6a and 10a show, the changes in ozone due to doubling the $\mathrm{CO}_{2}$ concentration is very similar in some parts of the mesosphere to those due to decrease in solar UV radiation. Specifically, in the summer hemisphere, both perturbations increase the $\mathrm{O}_{3}$ mixing ratio by up to $15 \%$ between 75 and $82 \mathrm{~km}$ and reduce it in the mesopause region. The differences become significant in the high-latitude winter throughout the mesosphere, owing to the differences in the response of $\mathrm{O}\left({ }^{3} \mathrm{P}\right), \mathrm{H}$, and $\mathrm{OH}$ in this region (see Figures $6 \mathrm{~b}-6 \mathrm{~d}$ and $10 \mathrm{~b}-10 \mathrm{e}$ ). For example, poleward of about $50^{\circ} \mathrm{N}$ near the mesopause region $\mathrm{O}_{3}$ mixing ratio increases from 5 to $40 \%$ when $\mathrm{CO}_{2}$ is doubled (due mostly to a very large increase in $\left.\mathrm{O}^{3} \mathrm{P}\right)$ ), whereas it decreases by $\sim 25 \%$ when solar UV irradiance decreases (due to both a substantial increase in $\mathrm{OH}$ and a decrease in $\left.\mathrm{O}\left({ }^{3} \mathrm{P}\right)\right)$. A significant difference exists in the lower mesosphere also, where ozone decreases by less than $5 \%$ below about $65 \mathrm{~km}$ when solar activity reaches a minimum, but it increases by up to $20 \%\left(60^{\circ} \mathrm{N}\right)$ when the $\mathrm{CO}_{2}$ abundance is doubled.

[60] Other similarities in the chemical response of the mesosphere exist as well. For example, $\mathrm{OH}$ increases substantially in both cases near the mesopause region across most latitudes (Figures $6 \mathrm{~b}$ and $10 \mathrm{~d}$ ), and both perturbations increase the water vapor abundance dramatically in the upper mesosphere lower thermosphere region (Figures 8a and 10c). Also, atomic hydrogen decreases in both cases in most of the mesosphere, although by varying amounts.

\section{Interaction Between $2 \times \mathrm{CO}_{2}$ and Solar Variability Perturbations}

[61] Another remarkable result from the doubled $\mathrm{CO}_{2}$ and solar cycle simulations concerns the degree of interaction between these two perturbations; i.e., the extent to which the effects of one perturbation influence those of the other. Since a comprehensive investigation of such interactions is outside the scope of this paper, we present here only a preliminary discussion of these results.

[62] Specifically, our calculations show that in most of the mesosphere the thermal and chemical effects of doubling $\mathrm{CO}_{2}$ and solar variability are additive (i.e., linear). Figures 11 and 12 illustrate this conclusion for the response of temperature, $\mathrm{O}_{3}, \mathrm{O}\left({ }^{3} \mathrm{P}\right), \mathrm{OH}, \mathrm{H}$, and total $\mathrm{H}\left(2\left[\mathrm{H}_{2} \mathrm{O}\right]+\right.$ $\left.4\left[\mathrm{CH}_{4}\right]+2\left[\mathrm{H}_{2}\right]+[\mathrm{H}]+[\mathrm{OH}]+\left[\mathrm{HO}_{2}\right]\right)$. For the left-hand panels in Figures 11 and 12, a simulation was run in which the $\mathrm{CO}_{2}$ mixing ratio was doubled and, additionally, the solar flux spectrum was reduced to the solar minimum values. The results were then compared with those of the solar maximum simulation with $1 \times \mathrm{CO}_{2}$. Thus, the lefthand panels show the effects of perturbing a $1 \times \mathrm{CO}_{2}$ atmosphere that is at solar maximum conditions by reducing the solar flux and doubling the $\mathrm{CO}_{2}$ mixing ratio at the same time; i.e., the combined perturbation. We then simulated 

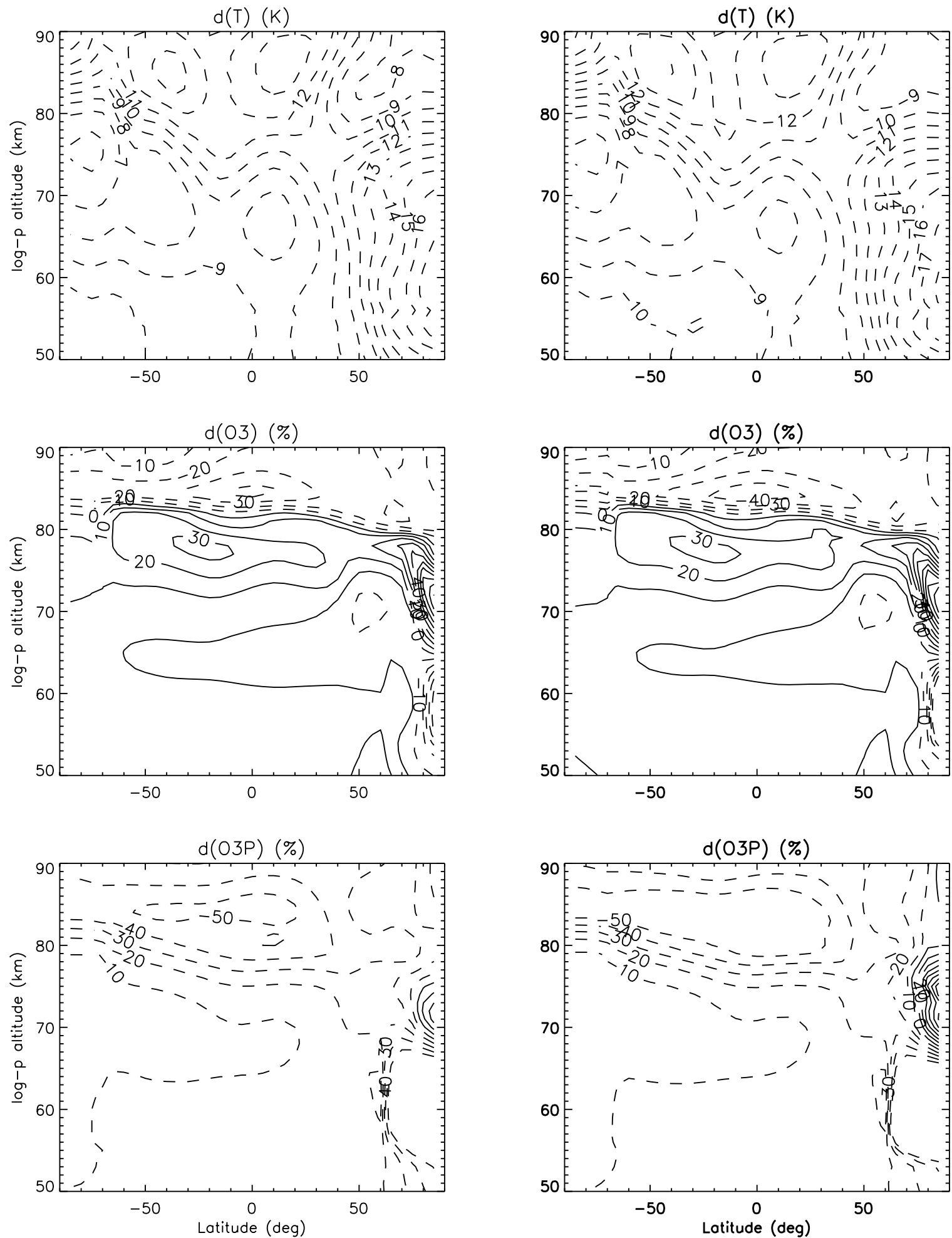

Figure 11. Interaction between doubling the $\mathrm{CO}_{2}$ mixing ratio and variability in solar UV flux. Lefthand panels show absolute change in $\mathrm{T}(\mathrm{K})$ and relative change $(\%)$ in $\mathrm{O}_{3}$ and $\mathrm{O}\left({ }^{3} \mathrm{P}\right)$ mixing ratios for January due to combined perturbations of $2 \times \mathrm{CO}_{2}$ and reduction of solar flux to solar minimum values. Right-hand panels show relative change in the same quantities when these two perturbations are simulated separately and their effects are added (see section 7). To obtain the effects of each individual perturbation, results of the corresponding simulation were compared with those of the $1 \times \mathrm{CO}_{2}$ at solar maximum case. 

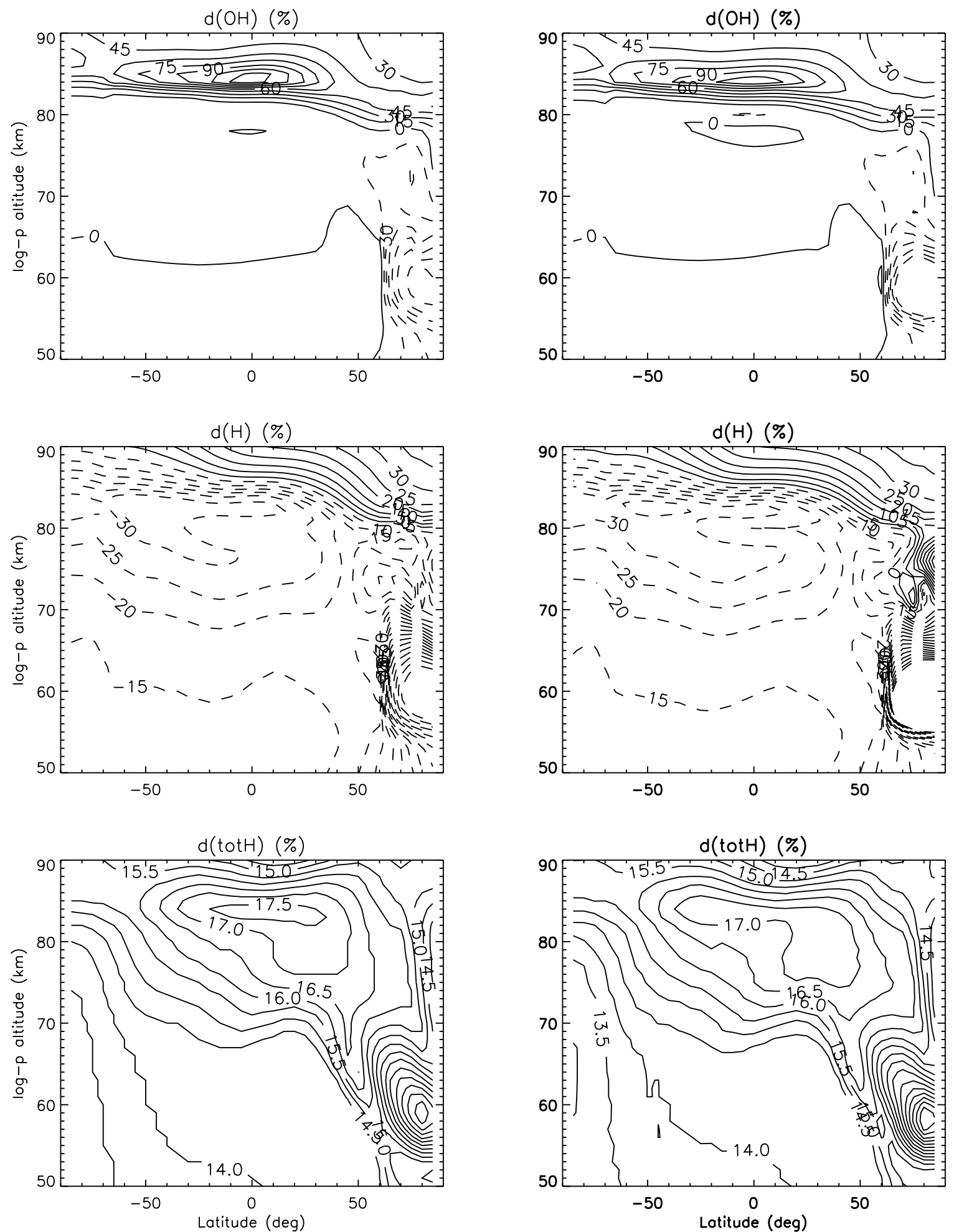

Figure 12. As in Figure 11, but for abundances of $\mathrm{OH}, \mathrm{H}$, and total $\mathrm{H}$ (defined as $2\left[\mathrm{H}_{2} \mathrm{O}\right]+4\left[\mathrm{CH}_{4}\right]+$ $\left.2\left[\mathrm{H}_{2}\right]+[\mathrm{H}]+[\mathrm{OH}]+\left[\mathrm{HO}_{2}\right]\right)$.

each of these perturbations individually and added the results, which are given in the right-hand panels in Figures 11 and 12 . Thus the right-hand panels show the sum of two effects on a $1 \times \mathrm{CO}_{2}$ atmosphere. One is perturbing it by reducing the solar flux only, and the other is perturbing it by doubling the $\mathrm{CO}_{2}$ mixing ratio only. In this way, the right- hand panels show the effects of the sum of the individual perturbations that were combined to yield the effects shown in the left-hand panels.

[63] Clearly, the sum of the effects of the individual perturbations is very nearly equal to the effects of the combined perturbation, in both structure and magnitude, 
for temperature, the $\mathrm{O}_{\mathrm{x}}$, and the $\mathrm{HO}_{\mathrm{x}}$ species. This implies that there is little interaction between these perturbations in the mesosphere so that their effects are additive.

[64] The implications of this result may be very important. Particularly, they suggest that, at least to first degree, the processes governing the observed thermal and chemical structure of the mesosphere may be linear. This would stand in sharp contrast to the highly nonlinear nature of the partial differential equations that are the basis of our understanding of the state and evolution of the atmosphere. Another important implication is that the effects of combined perturbations may be obtained, to a good approximation, by adding the individual effects, thus saving time and computing resources. Further research is necessary, however, to reveal the underlying fundamental reasons for this result and its generality.

\section{Summary and Conclusions}

[65] We have used the improved version of the NCAR 2D model, SOCRATES, to study the effects in the mesosphere of human-induced and natural perturbations. The human-induced changes are those of increase in the greenhouse gas concentrations and halocarbons since the preindustrial era, and doubling the $\mathrm{CO}_{2}$ abundance. The natural perturbation is the variability in the solar UV flux due to the sun's 11-year cycle. The model is well suited for these investigations since it simulates most of the important radiative, dynamical, and chemical processes that take place in the middle atmosphere, and treats the feedback between these processes interactively. It should be noted, however, that as an inherent limitation of 2-D models, the impact of perturbed mesospheric tides is not reflected in our results. In particular, changes in the strength of the tides that may be caused by the atmospheric perturbations could have important effects on the thermal structure and hence chemical composition of the upper mesosphere. These effects are best studied with interactive 3-D models of the middle atmosphere, an opportunity for future investigations of climate change in the mesosphere. Our results have shown the following.

[66] The increase in the abundance of the greenhouse gases, primarily $\mathrm{CO}_{2}$, from the preindustrial era to the present (section 5.1) has cooled the entire mesosphere by $\sim 5 \mathrm{~K}$ in the mesopause region and by up to $9 \mathrm{~K}$ at about 60 $\mathrm{km}$ in the winter polar latitudes. The warming of the tropical tropopause in the model that accompanies the $\mathrm{CO}_{2}$ increase, the higher $\mathrm{CH}_{4}$ abundance, and dynamical effects lead to a substantial increase in water vapor $(40-70 \%)$. As a result, the mixing ratios of $\mathrm{OH}$ and $\mathrm{H}$ increase significantly, which lead to a decrease in the $\mathrm{O}_{3}$ mixing ratio of up to $30 \%$ in the mesopause region.

[67] Even larger cooling occurs in the mesosphere when the $\mathrm{CO}_{2}$ abundance is doubled (section 5.2). The model calculations show a cooling of about $9 \mathrm{~K}$ in the tropical upper mesosphere, up to $16 \mathrm{~K}$ in the winter pole between 55 and $70 \mathrm{~km}$, and about $6 \mathrm{~K}$ in the high-latitude summer polar region. The results indicate that dynamical feedbacks play a significant role in this cooling, consistent with previous studies. Furthermore, substantial changes also occur in the chemical composition of the mesosphere. Ozone increases by $5-20 \%$ in the lower mesosphere, decreases by a few percent between 60 and $70 \mathrm{~km}$, increases by up to $15 \%$ between 70 and $80 \mathrm{~km}$, and decreases again by up to $20 \%$ in the mesopause region. This complicated response can be traced partly to the changes in the structure and magnitude of $\mathrm{OH}$ and $\mathrm{H}$ distributions, which are in turn caused by a substantial increase in water vapor.

[68] The effects of a decrease in solar UV flux from the maximum to the minimum of a typical 11-year cycle (section 5.3) are similar to those of doubling the $\mathrm{CO}_{2}$ mixing ratio. Ozone responds in a similar decrease/increase pattern as in the $2 \times \mathrm{CO}_{2}$ case. The range and latitudinal gradient of the cooling are significantly smaller than those in the doubled $\mathrm{CO}_{2}$ case. The magnitude and structure of the change in ozone is very similar in both cases for most of the mesosphere, particularly near the mesopause region. However, in the high-latitude winter mesosphere the ozone response is the opposite between the two cases.

[69] Finally, our results indicate that there may be little interaction between doubling the $\mathrm{CO}_{2}$ mixing ratio and solar variability (section 7) such that the response of $\mathrm{T}, \mathrm{O}_{3}, \mathrm{O}\left({ }^{3} \mathrm{P}\right)$, $\mathrm{OH}, \mathrm{H}$, and total $\mathrm{H}$ in most regions in the mesosphere due to these individual perturbations is nearly additive.

[70] These results lead to the following conclusions. The high degree of similarity in the response of the mesosphere to doubling the $\mathrm{CO}_{2}$ abundance and to 11-year solar flux variability suggests that climate change in the mesosphere may not be associated only with anthropogenic perturbations. It is therefore necessary to devise a set of criteria to identify which perturbation might be the cause of thermal and chemical change in the mesosphere. The cyclic nature of the variability in solar UV flux over decadal time scales suggests that a periodic signature in the observed response could be used to identify variations in solar activity as the perturbation causing the change. However, global measurements of constituents and temperature in the mesosphere that span many 11-year solar cycles do not yet exist in order to discern such signature with a high degree of confidence. Moreover, as pointed out by Lean and Rind [1998], variability in solar UV flux occurs not only on decadal time scales but may occur on centennial timescales as well. This complicates the situation because multidecadal solar variability has not been measured yet and remains very speculative [Lean, 2000]. Thus, the response of the mesosphere to the continued increase in the $\mathrm{CO}_{2}$ abundance during the $21 \mathrm{st}$ century may be difficult to discern. If the long-term trend of the solar UV flux is negative over the next several decades, when the $\mathrm{CO}_{2}$ abundance is expected to double, the two perturbations will enhance each other's effects on the temperature distribution and chemical composition of the mesosphere. However, if the long-term trend of the solar irradiance is positive, the response of the mesosphere to the continued increase in the $\mathrm{CO}_{2}$ concentration may be nearly canceled by that due to the increasing solar flux.

[71] Further data analyses and modeling studies are therefore necessary to clearly understand the cause(s) of the changes that have occurred in the thermal structure and chemical composition of the mesosphere, such as the observed cooling and increase in water vapor abundance. It is also essential to continue to monitor the state of the middle atmosphere and to measure the solar UV irradiance with high precision and stable instruments throughout the 
21 st century in order to rigorously study the changes that may be occurring in this region of the atmosphere.

[72] Acknowledgments. We thank Theresa Y. Huang for her contributions to the development of the current version of the SOCRATES model. We also thank Bill Randel, Mike Coffey, and two anonymous reviewers for making valuable comments and suggestions on improving the manuscript. Support for this research was provided by the NASA Office of Space Science. National Center for Atmospheric Research is operated by the University Corporation for Atmospheric Research under sponsorship of the National Science Foundation.

\section{References}

Akmaev, R. A., and V. I. Fomichev, Cooling of the mesosphere and lower thermosphere due to doubling of $\mathrm{CO}_{2}$, Ann. Geophys., 16, 1501-1512, 1998.

Akmaev, R. A., and V. I. Fomichev, A model estimate of cooling in the mesosphere and lower thermosphere due to the $\mathrm{CO}_{2}$ increase over the last 3-4 decades, Geophys. Res. Lett., 27, 2113-2116, 2000.

Barth, C. A., D. W. Rusch, R. J. Thomas, G. H. Mount, G. J. Rottman, G. E. Thomas, R. W. Saunders, and G. M. Lawrence, Solar Mesosphere Explorer: Scientific objectives and results, Geophys. Res. Lett., 10, $237-$ 240, 1983.

Berger, U., and M. Dameris, Cooling of the upper atmosphere due to $\mathrm{CO}_{2}$ increases: A model study, Ann. Geophys., 11, 809-819, 1993.

Brasseur, G. P., The response of the middle atmosphere to long-term and short-term solar variability: A two-dimensional model, J. Geophys. Res., 98, 23,079-23,090, 1993.

Brasseur, G. P., and M. H. Hitchman, Stratospheric response to trace gas perturbations: Changes in ozone and temperature distributions, Science, 240, 634-637, 1988

Brasseur, G. P., and D. Offermann, Recombination of atomic oxygen near the mesopause: Interpretation of rocket data, J. Geophys. Res., 91, 10,818-10,824, 1986.

Brasseur, G., and S. Solomon, Aeronomy of the Middle Atmosphere, D. Reidel, Norwell, Mass., 1986.

Brasseur, G., M. H. Hitchman, S. Walters, M. Dymek, E. Falise, and M. Pirre, An interactive chemical dynamical two-dimensional model of the middle atmosphere, J. Geophys. Res., 95, 5639-5655, 1990.

Brewer, A. M., Evidence for a world circulation provided by the measurements of helium and water vapor distribution in the stratosphere, $Q . J . R$ Meteorol. Soc., 75, 351-363, 1949.

Briegleb, B. P., Longwave band model for thermal radiation in climate studies, J. Geophys. Res., 97, 11,475-11,485, 1992.

Brühl, C., et al., Halogen Occultation Experiment ozone channel validation, J. Geophys. Res., 101, 10,217-10,240, 1996.

Chandra, S., C. H. Jackman, E. L. Fleming, and J. M. Russell III, The seasonal and long-term change in mesospheric water vapor, Geophys. Res. Lett., 24, 639-642, 1997.

DeMore, W. B., S. P. Sander, D. M. Golden, R. F. Hampson, M. J. Kurylo, C. J. Howard, A. R. Ravishankara, C. E. Kolb, and M. J. Molina, Chemical kinetics and photochemical data for use in stratospheric modeling, JPL Publ., 97-4, 1997.

Dunkerton, T. J., D. P. Delisi, and M. P. Baldwin, Middle atmosphere cooling trend in historical rocketsonde data, Geophys. Res. Lett., 25 , 3371-3374, 1998 .

Fels, S. B., J. D. Mahlman, M. D. Schwarzkopf, and R. W. Sinclair, Stratospheric sensitivity to perturbations in ozone and carbon dioxide: Radiative and dynamical response, J. Atmos. Sci., 37, 2265-2297, 1980.

Fomichev, V. I., G. M. Shved, and A. A. Kutepov, Radiative cooling of the 30-110 km atmospheric layer, J. Atmos. Sol. Terr. Phys., 48, 529-544, 1986.

Fomichev, V. I., J. P. Blanchet, and D. S. Turner, Matrix parameterization of the $15 \mu \mathrm{m} \mathrm{CO} \mathrm{CO}_{2}$ band cooling in the middle and upper atmosphere for variable $\mathrm{CO}_{2}$ concentration, J. Geophys. Res., 103, 11,505-11,528, 1998

Garcia, R. R., Parameterization of planetary wave breaking in the middle atmosphere, J. Atmos. Sci., 48, 1405-1419, 1991.

Garcia, R. R., and S. Solomon, A numerical model of the zonally averaged dynamical and chemical structure of the middle atmosphere, J. Geophys. Res., 88, 1379-1400, 1983.

Garcia, R. R., and S. Solomon, The effect of breaking gravity waves on the dynamics and chemical composition of the mesosphere and lower thermosphere, J. Geophys. Res., 90, 3850-3868, 1985.

Goody, R. M., and Y. L. Yung, Atmospheric Radiation, Oxford Univ. Press, New York, 1989.

Harries, J. E., J. M. Russell III, A. F. Tuck, L. L. Gordley, P. Purcell,
K. Stone, R. M. Bevilacqua, M. Gunson, G. Nedoluha, and W. A. Traub, Validation of measurements of water vapor from the Halogen Occultation Experiment (HALOE), J. Geophys. Res., 101, 10,205-10,216, 1996.

Hitchman, M. H., J. C. Gille, C. D. Rogers, and G. P. Brasseur, The separated polar winter stratopause: A gravity wave-driven climatological feature, J. Atmos. Sci., 46, 410-422, 1989.

Holton, J. R. The role of gravity-wave-induced drag and diffusion in the momentum budget of the mesosphere, J. Atmos. Sci., 39, 791-799, 1982.

Huang, T., et al., Description of SOCRATES-A chemical dynamical radiative two-dimensional model, NCAR Tech. Note TN-440 + EDD, Natl. Cent. for Atmos. Res., Boulder, Colo., 1998

Intergovernmental Panel on Climate Change (IPCC), Second assessment report-Climate change 1995, Intergov. Panel on Clim. Change, Geneva, 1995. (Available at http://www.ipcc.ch/pub/sarsyn.htm).

Joseph, J. H., W. J. Wiscombe, and J. A. Weinman, The delta-Eddington approximation for radiative flux transfer, J. Atmos. Sci., 33, 2450-2452, 1976.

Keckhut, P., and K. Kodera, Long-term changes of the upper stratosphere as seen by Japanese rocketsondes at Ryory $\left(39^{\circ} \mathrm{N}, 141^{\circ} \mathrm{E}\right)$, Ann. Geophys., 17, 1210-1217, 1999.

Kockarts, G., Penetration of solar radiation in the Schumann-Runge bands of molecular oxygen: A robust approximation, Ann. Geophys., 12, $1207-$ 1217, 1994.

Langner, J., H. Rodhe, and M. Olofsson, Parameterization of subgrid-scale vertical tracer transport in a global two-dimensional model of the troposphere, J. Geophys. Res., 95, 13,691-13,706, 1990.

Lean, J., Evolution of the Sun's spectral irradiance since the Maunder minimum, Geophys. Res. Lett., 27, 2425-2428, 2000.

Lean, J., and D. Rind, Climate forcing by changing solar radiation, J. Clim., 11, 3069-3094, 1998

Lindzen, R. S., Turbulence and stress owing to gravity wave and tidal breakdown, J. Geophys. Res., 86, 9707-9714, 1981.

Lindzen, R. S., and H. L. Kuo, A reliable method for the numerical integration of a large class of ordinary and partial differential equations, Mon. Weather Rev., 97, 732-734, 1969.

Lysenko, E. V., S. P. Perov, A. I. Semenov, N. N. Shefov, V. A. Sukhodoev, G. V. Givishvili, and L. N. Leshchenko, Long-term trends of the yearly mean temperature at heights from 25 to $100 \mathrm{~km}$, Atmos. Oceanic Phys., 35, 435-443, 1999.

McCormak, J. P., and L. Hood, Apparent solar cycle variations of upper stratospheric ozone and temperature: Latitude and seasonal dependences, J. Geophys. Res., 101, 20,933-20,944, 1996.

Meehl, G. A., W. D. Collins, B. A. Boville, J. T. Kiehl, T. M. L. Wigley, and J. M. Arblaster, Response of the NCAR climate system model to increased $\mathrm{CO}_{2}$ and the role of physical processes, J. Clim., 13, 18791898,2000

Mlynczak, M. G., and S. Solomon, A detailed evaluation of the heating efficiency in the middle atmosphere, J. Geophys. Res., 98, 10,517$10,541,1993$

Mote, P. W., K. H. Rosenlof, M. E. McIntyre, E. S. Carr, J. C. Gille, J. R. Holton, J. S. Kinnersley, H. C. Pumphrey, J. M. Russell III, and J. W. Waters, An atmospheric tape recorder: The imprint of tropical tropopause temperatures on stratospheric water vapor, J. Geophys. Res., 101, 39894006, 1996.

Nedoluha, G. E., R. M. Bevilacqua, R. M. Gomez, D. E. Siskind, B. C. Hicks, J. M. Russell III, and B. J. Connor, Increases in middle atmospheric water vapor as observed by the Halogen Occultation Experiment and the ground-based water vapor millimeter-wave spectrometer from 1991 to 1997, J. Geophys. Res., 103, 3531-3543, 1998.

Park, J. H., et al., Validation of Halogen Occultation Experiment $\mathrm{CH}_{4}$ measurements from the UARS, J. Geophys. Res., 101, 10,183-10,203, 1996.

Portmann, R. W., G. E. Thomas, S. Solomon, and R. R. Garcia, The importance of dynamical feedbacks on doubled $\mathrm{CO}_{2}$-induced changes in the thermal structure of the mesosphere, Geophys. Res. Lett., 22, 1733-1736, 1995.

Randel, W. J., Global atmospheric circulation statistics, 1000-1 mb, NCAR Tech. Note TN-295, 245 pp., Natl. Cent. for Atmos. Res., Boulder, Colo., 1987.

Randel, W. J., Global atmospheric circulation statistics, 1000-1 mb, NCAR Tech. Note TN-366 + STR, 256 pp., Natl. Cent. for Atmos. Res., Boulder, Colo., 1992.

Reber, C. A., The Upper Atmosphere Research Satellite (UARS), Geophys. Res. Lett., 20, 1215-1218, 1993

Rind, D., R. Suozzo, N. K. Balachandran, and M. J. Prather, Climate change and the middle atmosphere, part I, The doubled $\mathrm{CO}_{2}$ climate, J. Atmos. Sci., 47, 475-494, 1990.

Rind, D., D. Shindell, P. Lonergan, and N. K. Balachandran, Climate change and the middle atmosphere, part III, The doubled $\mathrm{CO}_{2}$ climate revisited, J. Clim., 11, 876-894, 1998 . 
Robert, A., A stable numerical integration scheme for the primitive meteorological equations, Atmos. Ocean, 10, 35-46, 1981.

Roble, R. G., and R. E. Dickinson, How will changes in carbon dioxide and methane modify the mean structure of the mesosphere and thermosphere, Geophys. Res. Lett., 16, 1441-1444, 1989.

Rottman, G., Observations of solar UV and EUV variability, Adv. Space Res., 8, 53-66, 1988 .

Russell, J. M., III, L. L. Gordley, J. H. Park, S. R. Drayson, W. D. Hesketh, R. J. Cicerone, A. F. Tuck, J. E. Frederick, J. E. Harries, and P. J. Crutzen, The halogen occultation experiment, J. Geophys. Res., 98, 10,77710,797, 1993

Shettle, E. P., and J. A. Weinman, The transfer of solar irradiance through inhomogeneous turbid atmospheres evaluated by Eddington's approximation, J. Atmos. Sci., 27, 1048-1055, 1970.

Shindell, D. T., D. Rind, and P. Lonergan, Climate change and the middle atmosphere, part IV, Ozone response to doubled $\mathrm{CO}_{2}$, J. Clim., 11, 895918, 1998a.

Shindell, D. T., D. Rind, and P. Lonergan, Increased polar stratospheric ozone losses and delayed eventual recovery owing to increasing greenhouse-gas concentrations, Nature, 329, 589-592, $1998 \mathrm{~b}$

Shindell, D. T., G. A. Schmidt, R. L. Miller, and D. Rind, Northern Hemisphere winter climate response to greenhouse gas, ozone, solar, and volcanic forcing, J. Geophys. Res., 106, 7193-7210, 2001.

Siskind, D. E., C. A. Barth, and J. M. Russell III, A climatology of nitric oxide in the mesosphere and thermosphere, Adv. Space Res., 21, $1353-$ $1362,1998$.

Smith, A. K., and S. K. Avery, A resonant wave in a numerical model of the 1979 sudden stratospheric warming, J. Atmos. Sci., 44, 3150-3161, 1987.

Soon, W. B., L. Sallie, A. B. Robinson, and Z. W. Robinson, Environmental effects of increased atmospheric carbon dioxide, Clim. Res., 13, 149164, 1999.

Summers, M. E., D. F. Strobel, R. M. Bevilacqua, X. Zhu, M. T. DeLand,
M. Allen, and G. M. Keating, A model study of the response of mesospheric ozone to short-term solar ultraviolet flux variations, J. Geophys. Res., 95, 22,523-22,538, 1990.

Thomas, G. E., Global change in the mesosphere-lower thermosphere region: Has it already arrived?, J. Atmos. Sol. Terr. Phys., 58, 1629-1656, 1996.

Washington, W. M., and G. A. Meehl, Climate sensitivity due to increased $\mathrm{CO}_{2}$ : Experiments with a coupled atmosphere and ocean general circulation model, Clim. Dyn., 4, 1-38, 1989.

Woods, T. N., et al., Validation of the UARS solar ultraviolet irradiances: Comparison with the ATLAS 1 and 2 measurements, J. Geophys. Res., 101, 9541-9569, 1996.

World Meteorological Organization, Atmospheric ozone 1985, Rep. 16 , Global Ozone Res. and Monit. Proj., Geneva, 1986.

World Meteorological Organization, Scientific assessment of ozone depletion: 1998, Rep. 44, Global Ozone Res. and Monit. Proj., Geneva, 1998.

Yulaeva, E., J. R. Holton, and J. M. Wallace, On the cause of the annual cycle in tropical lower stratospheric temperatures, J. Atmos. Sci., 51, $169-174,1994$

G. Brasseur, Max Planck Institute for Meteorology, Bundesstrasse 55, D-20146, Hamburg, Germany. (brasseur@dkrz.de)

S. Chabrillat and G. Kockarts, Belgian Institute for Space Aeronomy, 3 Avenue Circulaire, B-110 Brussels, Belgium. (simonc@oma.be; Gaston. Kockarts@oma.be)

R. Khosravi, A. Smith, and S. Walters, National Center for Atmospheric Research, P.O. Box 3000, Boulder, CO 80307-3000, USA. (rashid@ucar. edu; aksmith@ucar.edu; stacy@ucar.edu)

D. Rusch, Laboratory for Atmospheric and Space Physics, University of Colorado, Boulder, CO 80309, USA. (David.Rusch@lasp.colorado.edu) 